\title{
State history and economic development: evidence from six millennia
}

\author{
Oana Borcan $^{1} \cdot$ Ola Olsson $^{2}$ (D) $\cdot$ Louis Putterman ${ }^{3}$
}

(C) The Author(s) 2017. This article is an open access publication

\begin{abstract}
The presence of a state is one of the most reliable historical predictors of social and economic development. In this article, we complete the coding of an extant indicator of state presence from $3500 \mathrm{BCE}$ forward for almost all but the smallest countries of the world today. We outline a theoretical framework where accumulated state experience increases aggregate productivity in individual countries but where newer or relatively inexperienced states can reach a higher productivity maximum by learning from the experience of older states. The predicted pattern of comparative development is tested in an empirical analysis where we introduce our extended state history variable. Our key finding is that the current level of economic development across countries has a hump-shaped relationship with accumulated state history.
\end{abstract}

Keywords State history $\cdot$ Comparative development $\cdot$ Institutions $\cdot$ Deep roots

JEL Classification $\mathrm{O} 11 \cdot \mathrm{O} 43 \cdot \mathrm{O} 50 \cdot \mathrm{N} 00$

We are grateful for useful comments from Carl-Johan Dalgaard, Jakob Gerner Hariri, Sascha Becker and four anonymous referees and from seminar participants at University of Copenhagen and Brown University. We also thank Taewan Roh and Nicholas Carter for valuable research assistance.

Electronic supplementary material The online version of this article (https://doi.org/10.1007/s10887017-9152-0) contains supplementary material, which is available to authorized users.

\section{Ola Olsson}

ola.olsson@economics.gu.se

1 School of Economics, University of East Anglia, Norwich, UK

2 Department of Economics, University of Gothenburg, Box 630, 40530 Göteborg, Sweden

3 Department of Economics, Brown University, Providence, RI, USA 


\section{Introduction}

History has shown that economic development often thrives in states where governments guarantee the rule of law and provide public goods for their citizens. In order to reach a deeper understanding of why some countries have good government and others do not, social scientists have become increasingly interested in studying the long-run patterns of institutional development within states. The roots of countries' contemporary failures or successes have often been traced back to "critical junctures" far back in history. ${ }^{1}$

In this paper, we analyze how state development has interacted with economic development. More specifically, we attempt to make two distinct contributions to the literature. First, we provide a complete state history index from its first origin around 3500 BCE up until the present day. Initially developed by Bockstette et al. (2002) for 159 countries, the index covered the period 1-1950 CE. We extend the index from $1 \mathrm{CE}$ backwards in time to the first origins of states around $3500 \mathrm{BCE}$ and also code the 1951-2000 CE period, which was previously missing from the time series.

Second, we investigate how our extended state history index is related to indicators of long-run economic development. The key hypothesis from our theoretical framework is that modern levels of productivity and population density should have a hump-shaped relationship with the extent of state history. We expect non-linear effects of state experience in the preindustrial era, and we predict it develops into a hump-shaped relationship by $2000 \mathrm{CE}$. In the empirical section, we then confirm that the relationship between our state history index and current levels of economic development has the shape of an inverted $u$, implying that countries with very much or very little state experience have the least developed economies whereas the richest countries have intermediate state history scores.

For the first of these objectives - the creation of a state history index for the BCE-period, we follow the methodology in the original effort by Bockstette et al. (2002). This combines three dimensions of state development: (1) The existence of a state above tribal level; (2) Whether rule was internally or externally based (i.e. whether a country's territory had an autonomous government or was ruled partly or fully by an authority outside of its borders); (3) How much of its territory was under the control of a government (as opposed to multiple competing governments and regions still lacking state presence). The three indicators were coded for each of the 159 countries in our sample and for each 50-year period from the origin of the first states around $3500 \mathrm{BCE}$, yielding a panel data set with 17,490 country-period observations. The details of the sources for and construction of the index are described further below.

Our second objective hinged crucially on extending the state history data initially compiled by Bockstette et al. (2002). Their study was the first to show a significant correlation between state history and recent growth rate and between state history and income level. The numerous studies that followed strengthened the evidence that current development is positively related to state experience. Although subsequent versions of the index used in these papers expanded the set of countries, none coded the history of states BCE.

With these developments in mind and with the new data on the extended state history index, we revisit the relationship between the degree of exposure to state institutions and current output. We show that the relationship between state history and current income per capita across countries is hump-shaped rather than linear, and that this is due to the inclusion of state experience before the Common Era. Thus, in addition to young, inexperienced states,

1 See for instance North (1990), Acemoglu et al. (2005), Acemoglu and Robinson (2012), and Besley and Persson (2009). 
very old states also incur economic disadvantages relative to states with around 2000 years of state experience.

Our inquiry is supported by the empirical observation that countries having long state experience like Iraq, Turkey and China are poorer today than younger states like Britain, Denmark and Japan, a fact that remained unexplained in previous work. The early experience of the former was uncoded in the previous data, which effectively forced countries having much more state experience to take similar values to ones having intermediate levels, such as England (the UK).

Building on previous literature, we contribute additional knowledge about the influence of early political and societal development on modern economic development. In a stylized theoretical framework, we argue the earliest states developed the fiscal capacity and coordination needed to achieve increases in productivity, but ultimately limited that productivity due to overcentralization. Although earlier states became stagnant, younger states were able to learn from them and surpass their productivity before they reached stagnation themselves. By contrast, very young states early in the process of building fiscal and institutional capacity, are at a relative disadvantage. Thus, along with young states, a very long state experience also comes with economic disadvantages relative to countries with intermediate state experience. We show that this more complex relationship starts to be visible with respect to economic development indicators (population density and urbanization) and technology adoption in $1500 \mathrm{CE}$, but it clearly reveals itself in $2000 \mathrm{CE}$ economic performance. Moreover, the relationship for current outcomes is further strengthened when adjusting the index for the ancestral lines of post-1500 migrant populations. ${ }^{2}$

The work clearly involves several methodological challenges. For instance, how should a state be defined? In this regard, we follow the tradition of Service (1962), Carneiro (1981), Johnson and Earle (2000) and others, distinguishing between bands, chiefdoms, and fullfledged states. Unlike the other forms of governments, states are further characterized by a centralized government with the ability to collect taxes, enforce laws, and mobilize forces for war. Using this definition, the literature seems to be in rough agreement about the time when states arise in different countries. Accompanying this paper is an extensive online data appendix where we motivate the coding for each country-period observation.

Another issue concerns the unit of analysis, which is the territory delimited by the modernday country borders of 159 contemporary countries in the sample. It is a well-known fact that the borders of current countries sometimes have very little resemblance with the geopolitical logic in ancient times. As discussed in Sect. 5.4, several factors have played decisive roles in the reconfiguration of borders through history, including military conquest and colonization by foreign powers. We discuss the potential risks associated with shifting borders, in terms of retroactive measurement error for historical outcomes and bias in the estimates for contemporaneous outcomes.

A potential alternative to using country borders could have been to divide the world into equal-sized grid cells (or "virtual countries") and then study the history of each such cell. This would however entail a separate set of coding challenges that we leave for future work. The problem of endogenous borders is arguably somewhat mitigated in regressions with contemporaneous outcome variables since most countries actually have changed their borders throughout history. We would further argue that to the extent that researchers are interested in tracking the histories of countries in order to understand contemporary levels of development, the modern configuration of countries is still a natural point of departure.

2 Olsson and Paik (2013) hint at this relationship, showing a "reversal of fortune" of countries that made an early Neolithic transition. The idea of economic reversal was also discussed by Acemoglu et al. (2001) and Hariri (2012). 
The paper is organized as follows: In Sect. 2, we provide an overview of the literature on the definition of a state and the relationship of state history to economic development. In Sect. 3, we present our theoretical framework. In Sect. 4 we present the new data and the principles guiding its construction. In Sect. 5, we carry out an econometric analysis of the relationship between economic development and state history. Section 6 concludes.

\section{Literature review}

\subsection{State history and economic development}

It is a well established empirical fact that history has shaped the contemporary economic development of nations in numerous ways. Whether initial biogeographic endowment and transition to agriculture (e.g. Hibbs and Olsson 2004; Olsson and Hibbs 2005; Galor and Moav 2007) or past technology adoption (Comin et al. 2010), early and productive starts have been typically shown to translate into better income and institutions in present times.

The experience with state institutions has been put forth as one of the important correlates of the current wealth distribution in the world. Specifically, from its original development, the State antiquity index of Bockstette et al. (2002) was shown to be positively associated with 1995 income and with the 1960-1995 GDP growth rate. Bockstette et al.'s aim was to use presence and duration of experience with macro polities as one of several potential indicators of societal complexity and level of technological advancement. The authors were interested in investigating the effect of early social and technological development on postWW2 economic growth rates, and they assumed that the impact of very early experience would decay over time, so they did not attempt to code information on state presence before $1 \mathrm{CE}$ or after 1950. They coded all countries with substantial populations for which relevant economic growth and other indicators were available, resulting in a sample of 104 countries, of which their analysis focused especially on 70 non-OECD member countries.

Roughly the same data set was also used by Chanda and Putterman (2005), and Chanda and Putterman (2007). Bockstette et al.'s data were subsequently expanded to include more ex-Communist countries (Iliev and Putterman 2007), more African countries (Cinyabuguma and Putterman 2011), and a few other countries for which complementary income or other required data had initially been viewed as unreliable. Based on this extended dataset, Putterman and Weil (2010) demonstrated that the ability of state history to predict current levels of development is greatly strengthened by replacing the state history that transpired on a given country's territory by the weighted average state history of the places in which current residents' ancestors lived in the past. This adjustment was motivated by the large movements of populations especially from "Old World" continents to the Americas, Australia and New Zealand after 1500. Chanda et al. (2014) apply the same procedure to demonstrate "persistence of fortune" of ancestral lines in former colonies that display a "reversal of fortune" (Acemoglu et al. 2002) in the absence of such ancestry and migration accounting. ${ }^{3}$

In short, previous work has largely agreed on a positive association between long-run state history and current development. However, as scholars have acknowledged, the present shares complex links with the past. For instance, pre-1500 economic advantages seem to have become relative disadvantages among colonized countries during the colonial era (Ace-

3 The state history data have also been employed in a number of other studies, receiving focal attention in Ang (2013a,b), playing important roles in Ahlerup and Olsson (2012), Hariri (2012), Ertan et al. (2016), and Daniele (2013), and being included as a control in a number of other studies. None of the above studies attempts to extend the information on states to include the BCE years or fill in the last half of the 20th Century. 
moglu et al. 2001, 2002). As of late, this idea of reversal has been revisited in two studies that are particularly relevant to our paper: Hariri (2012) presents compelling evidence that early (precolonial) experience of state institutions in countries outside Europe prevented them from transplanting democratic institutions brought by European colonizers, leaving instead an "autocratic legacy" in these countries. Olsson and Paik (2013) reveal a negative association between the time from Neolithic transition and current income levels in the Western agricultural core-Europe, North Africa and Southwestern Asia.

Furthermore, the long-run persistence literature has begun to reveal nonlinearities in how events in the very distant past affect economic development. For instance, the migration out of Africa is argued to have generated a wide array of genetic diversity levels in human populations around the world. In turn, predicted genetic diversity displays a hump-shaped relationship with indicators of economic development, including per capita income in 2000 (Ashraf and Galor 2013).

Thus, in light of these recent developments, allowing for a more flexible relationship between state history and contemporaneous levels of development is a natural extension to the literature. The closest paper to ours to have done so is Lagerlöf (2016), which presented simulations of a theoretical model consistent with a hump-shaped relationship where old states with a large extractive capacity and autocratic elites have been overtaken by younger and more democratic states with a greater growth potential. The empirical evidence hints at a concave relationship between contemporary income levels and state history in a crosscountry sample, based on the 1-1950 CE state history index, but only when adjusted for post-1500 migration.

In the theoretical section, we present a framework outlining how states affect and are affected by economic development over history and in the empirical section we explore systematically this relationship considering the complete state histories.

\subsection{Defining the "state"}

How do we know when a state has emerged? The first challenge stems from the question of how to define the state, hardly a novel dilemma in social sciences. The classical understanding of the "state" comes from Max Weber, who defined it as an entity which "upholds the claim to the monopoly of the legitimate use of physical force in the enforcement of its order" (Weber 1968, p. 54). This implies that we should be looking for evidence of the initial monopolization of power within a certain territory.

However, there is also the question of the extent of this original jurisdiction: how large is the population or the territory subject to the power monopoly? Is, for instance, a village with 100 tribesmen, led by a chief, large enough to classify as "state"? It appears that we need to find an appropriate threshold to distinguish between small and large scale political organization. Therefore we adopt the convention that, although simple chiefdoms fall short of being states, a paramount chiefdom which incorporates multiple individually substantial chiefdoms can be understood as a form of incipient state. Hence we decided to begin according partial weight when a polity reaches this level. By this convention, for instance, the land of what is today Belgium came under large-scale political organization for the first time between 59 and 52 $\mathrm{BCE}$, when it was integrated in the Roman Empire.

This agrees with established sociological and anthropological taxonomies of human societies throughout their evolution. For instance, Johnson and Earle (2000) proposed a division of societies into small-scale local group (further divided into family, village and the Big Man group) and larger-scale regional polity, which can be a chiefdom or a state. This distinction goes back even earlier, to Charles Tilly: "the term [state] includes city-states, empires, theoc- 
racies, and many other forms of government, but excludes tribes," (Tilly 1990, p. 1) and to Service's (1962) proposed typology of bands/tribes/chiefdoms/states. ${ }^{4}$

\section{Theoretical framework}

In this section, we outline the theoretical framework underlying the empirical analysis. We present the three basic premises of the model and then use four country case studies to illustrate the kind of dynamics that we have in mind which eventually produce a hump-shaped hypothesized relationship between state history and indicators of aggregate productivity. In the third subsection, we explain briefly how our intuitive framework fits into a more standard Malthusian growth model.

\subsection{The basic premises}

The key assumption of our framework is that up to a point, accumulated state history favors capacity building, taxation and the provision of public goods, which in turn spur economic growth. But beyond a certain level, state experience is conducive to the rise of extractive institutions and powerful elites that appropriate tax revenue rather than turn it into public goods. In the absence of constraining institutions, excessive centralization ultimately leads the state into stagnation. When more experienced states have reached this level, they tend to be overtaken by less experienced states still in their expansion phase (as bottom-up pressures in the latter bring about executive constraints). Of course, the state as such is not the only driver of growth, for example processes of technological improvement and trade expansion promoted in neighboring states may spill over to nearby areas. We nonetheless emphasize state experience as it is our focal empirical measure and it represents a key dimension of the development process over the very long run. We note again that by "state experience" we refer not only to duration of presence of macro polities, but also degree of unity, territorial coverage, and locally rather than externally based rule.

The proposed relationship between state history and long-run economic development has three distinct premises: (1) In a newly established state, an increase in fiscal and institutional capacity and in central coordination from low levels have historically been conducive to productivity increases and economic growth. (2) Governments in long enduring states often tend to misuse the tax revenue at the expense of economic progress, despite having access to a solid fiscal capacity. (3) Citizens of countries having less powerfully consolidated states can exploit the experience and mistakes of countries with greater degrees of internally-imposed power centralization, to advance their levels of productivity beyond the maximum reached by the latter. We discuss the evidence supporting these premises below.

First, there is widespread agreement that a very short state history, especially if characterized by a lack of autonomy and rule instability generally implies weaker fiscal capacity. This has recently been discussed among others by Tilly (1990), Collier (2009), and Besley and Persson (2013). Increasing evidence shows that a consolidated bureaucracy enables investments in large public projects, technological innovation, and effective warfare, thus spurring economic growth. Recent empirical studies on the historical role of state capacity reveal strong correlations and potential causal links between administrative infrastructure, high taxes and economic prosperity (Besley and Persson 2013; Dincecco and Katz 2014).

\footnotetext{
4 We thank Jacob Gerner Hariri for useful references on the matter of state definition.
} 
Second, older and more autonomous states are more predisposed to maintain overly centralized, often abusive power structures. The first states developed naturally from the basic need to sustain collective action in large communities, particularly in response to attacks by predators (Tilly 1990 and Olson 1993 and more recently, Mayshar et al. 2015). Against "roving bandits," it was welfare enhancing to have a member of the community become the dictator who collected rents used partly for defense, but mostly for self-gratification ("stationary bandit"). However, without mechanisms to commit to providing a certain level of public good, the autocrat became a "roving bandit," maximizing rent-extraction. Hence, as Olson concludes, in an autocracy good economic performance is unsustainable in the long run.

Examples of political and economic collapse in ancient states due to overcentralization abound. For instance, the demise of the expansive Mesopotamian empire Ur III (c. 2000 BCE) came when local city-states sought independence, rejecting the overbearing supercentralized bureaucracy tailored to channel resources from the periphery to Ur and finance the defense of conquered regions (Yoffee 1988). Similarly, only a few centuries later Hammurabi's great empire collapsed after disempowered local authorities rebelled against the drain on resources for the king's glorification in Babylon, plunging the state into an irreversible economic crisis (c. 1600 BCE).

Complementary evidence comes from Hariri (2012) who shows that older indigenously formed states were more likely to develop autocratic institutions than later states. His proposed channel is that older states more successfully fended off attempts at colonization by European powers between the 15th and 20th centuries, and hence did not experience either direct transplantation of or cultural influence related to conceptions of democratic institutions (developed between the 18th and 20th centuries within the Western colonizing powers).

Non-inclusive institutions and political instability also undermine fiscal capacity (see e.g. Besley and Persson 2013 and Dincecco and Katz 2014). ${ }^{5}$ Early states incurred frequent regime changes due to predatory attacks and internal strife. ${ }^{6}$ Moreover, ancient warfare did not stimulate tax collection to the same extent modern warfare does (Gennaioli and Voth 2015). Lacking sustainable revenue generation and constraints against turning resources away from public goods and technological innovation made earlier states more vulnerable to economic stagnation and collapse.

Third, we argue that countries with less state experience tend to be able to reach a higher level of development than countries with more (and usually longer) state experience before their stagnation phase sets in. This is supported by the pattern of superior economic development in countries with an intermediate length of a civilization, like the United Kingdom and the Scandinavian countries, compared to countries like Egypt or Iraq, as discussed in recent work by Olsson and Paik (2013). ${ }^{7}$ Again, the main arguments here are institutional: Olsson and Paik argue that old civilizations developed autocratic, hierarchical societies that were not conducive to the emergence of democracy and innovation, which became critical factors for economic growth during the modern era, leading to a "Western reversal of fortune" since the

\footnotetext{
5 Using data from 11 European countries for 1600-1913, Dincecco and Katz (2014) present causal evidence that historical reforms of tax centralization and, to some extent, constraints on the executive, led to higher tax revenue and improved infrastructure provision, which then stimulated economic growth. By contrast, states with more autonomous regional authorities generated smaller revenues.

6 Our statehist index captures political fragmentation (simultaneous existence of multiple states within a territory) through a downgrade in the territorial component, and reflects capture by external empires through a downgrade in the internal rule component.

7 Olsson and Paik (2013) also present preliminary evidence for overtaking of older by younger states in East Asia and in Sub-Saharan Africa.
} 
onset of agriculture. ${ }^{8}$ Similarly, Lagerlöf (2016) argues the autocratic elite in old states made repeated investments in extractive capacity, while the lack of a similar extractive capacity in younger states facilitates the transition to a faster-growing democracy. Democratic political structures with constraints on executive power may have developed in initially peripheral areas like England, the Netherlands and Scandinavia, because local and commercial elites effectively countered tendencies towards power centralization during the maturation process of these younger nation-states. Executive constraints, in turn, set the premise for unhindered technological innovation and may have mitigated the economic downturns accompanying domestic struggles for political leadership (Cox and Weingast 2015).

The regions once peripheral to the more ancient civilizations, slower to develop state institutions, were also less exposed to raids by roaming armies and to incursions by migrating peoples (such as the Persian, Hellenic, Hun, Islamic, Mongol and Turkic incursions in the old civilizational core regions). All these factors contributed to their ability to eventually overtake the levels of development in the older states. ${ }^{9}$

\subsection{The predicted pattern}

The three central factors discussed above combine to form the basis of a stylized pattern of state history and economic development. Figure 1a showcases this pattern, using four current countries, all located in the Western agricultural spread zone, ${ }^{10}$ as case studies. We assume, for simplicity, a logistic, positive relationship between state history and aggregate productivity in the spirit of existing long-run models. ${ }^{11}$ We do not, however, argue that every country necessarily follows this proximate pattern. Needless to say, the short account below does not have any ambition of providing a full description of the histories of Egypt, Italy, United Kingdom and Estonia. Please see the extensive Data Appendix for details about state development and our coding of historical events. Although we only use four examples, we do argue that the model below is applicable in broad outline also to the rest of the world. ${ }^{12}$

To the far left in the figure, we use Egypt as an example of a very old civilization where the first signs of a state-like organization above tribal level emerged around 3200 BCE. From a low pre-state level of development, total productivity in the economy started to increase when the government of a full state was able to extract taxes from the population that, in turn, were transformed into public goods that provided security and a more efficient mode of agricultural production. A few centuries after the origins of the state, development took

\footnotetext{
8 Wittfogel's (1957) "hydraulic hypothesis" makes the related argument that the old riverine civilizations were autocratic due to the technological nature of large-scale irrigation. See also Acemoglu and Robinson (2012) for an analysis of how countries with inclusive, democratic institutions eventually tend to dominate countries with extractive, autocratic institutions.

9 Olsson and Paik (2016) further argue that an early transition to agriculture led to the outbreak of several new infectious diseases which probably killed numerous inhabitants in the growing farming villages. The prevalence of infectious disease most likely also contributed to a collectivist culture with a strong in-group orientation and a suspicious attitude towards strangers and new ideas. But the impact of disease may have been different in late medieval/early modern Europe; see Voigtlander and Voth (2013).

10 That is, countries whose first adoption of agriculture was based on the Fertile Crescent package of crops and domesticated animals, as opposed to that of China, Mesoamerica, etc. See Hibbs and Olsson (2004) and Diamond (1997).

11 The logistic curve, with its implied take-off and maturity stages, is similar in spirit to the account in Rostow (1960). However, unlike Rostow, our model deals primarily with long history including pre-industrial development.

12 In a previous version of the paper, we modelled explicitly how fiscal capacity and central coordination of economic activities interacted with total factor productivity in a full Malthusian growth model.
} 
off in the classic period of the Old Kingdom with large cities, massive public monuments, codified language and a highly stratified, complex society.

However, as outlined in detail in our Data Appendix, the centralized government of Egypt began to run into problems by $2130 \mathrm{BCE}$ during the 8 th dynasty, when a decades-long drought and famine set off the fragmentation of central power. Repeated foreign invasions from the Hyksos in $1650 \mathrm{BCE}$ and onwards implied that Egypt gradually lost its economic and military dominance over the region, until a succession of foreign invaders such as the Assyrians, Persians, Macedonians, and Romans caused a marked slowdown in productivity growth. During the first millennium BCE, Egypt arguably started its long period of stagnation, characterized by slower productivity growth than the civilizations on the northern rim of the Mediterranean, which has by and large persisted to the present. By $1 \mathrm{CE}$, the Romans had conquered all lands around the Mediterranean and had surpassed the Egyptians technologically, militarily, and also in terms of state organization.

State origins in Italy can be traced back to the Etruscans in 850 BCE, more than two thousand years after similar developments in Egypt. As is well known, the Roman republic with its innovative political institutions and military organization, would soon become the greatest empire in Western Eurasia and forcefully dominate the lands around the Mediterranean. Economic stagnation set in with the dissolution of the Western Roman Empire circa $476 \mathrm{CE}$. While historians still argue about the main causes, it appears that political fragmentation and power struggles between the Church, senatorial aristocracy and the military led to territorial concessions to the barbarian invaders, a weakening of fiscal capacity and ultimately economic bankruptcy. ${ }^{13}$ However, as seen in our stylized figure, Italy long continued to be the most developed country among our four countries even after the fall of Rome. The barbarian tribes that invaded Rome soon tried to mimic Roman traditions and Latin lived on as a lingua franca for centuries due to the rising power of the Pope in the Vatican. Merchant sea powers such as Venice and Genoa would become very powerful in the early Medieval period and the Renaissance period was still a very innovative period in the history of the Italian peninsula, with progress in many fields.

However, with the emergence of Protestantism in northern Europe, the discovery of new trading routes on the Atlantic, and the increasing power of emerging centralized states in France and Britain, Italy started its period of economic and technological stagnation. ${ }^{14} \mathrm{Com}-$ pared to Italy, the emergence of a centralized state in Britain came quite late, beginning with external governance by Rome around $50 \mathrm{BCE}$ and internal polities from AD 401. Spurred by revenues from Atlantic trade and from institutional innovations that strengthened private property rights and accountable political institutions, Britain rose to eventually become the leading power in the world after the Napoleonic wars ended in 1815. The cluster of innovations that formed the backbone of the Industrial Revolution contributed to a dramatic rise in output per capita and to the breakdown of the Malthusian link between income levels and fertility. After World War I, the United Kingdom arguably entered a phase of relative stagnation in which it clearly lagged behind, for instance, the United States.

The territory of current Estonia was populated by tribes with no organized government until 1237, when the area was taken by Denmark and by German knights. Sweden and Russia then controlled the region until 1919 when Estonia experienced a brief period of independence, before it was once again swallowed by the Soviet Union after World War

13 See Yoffee (1988) for a brief discussion of the political decline and economic transformation of the Western Roman Empire.

14 See Puga and Trefler (2014) for an account of how a change in political institutions that increased the power of a small elite, led to the gradual decline of Venice after 1297. 

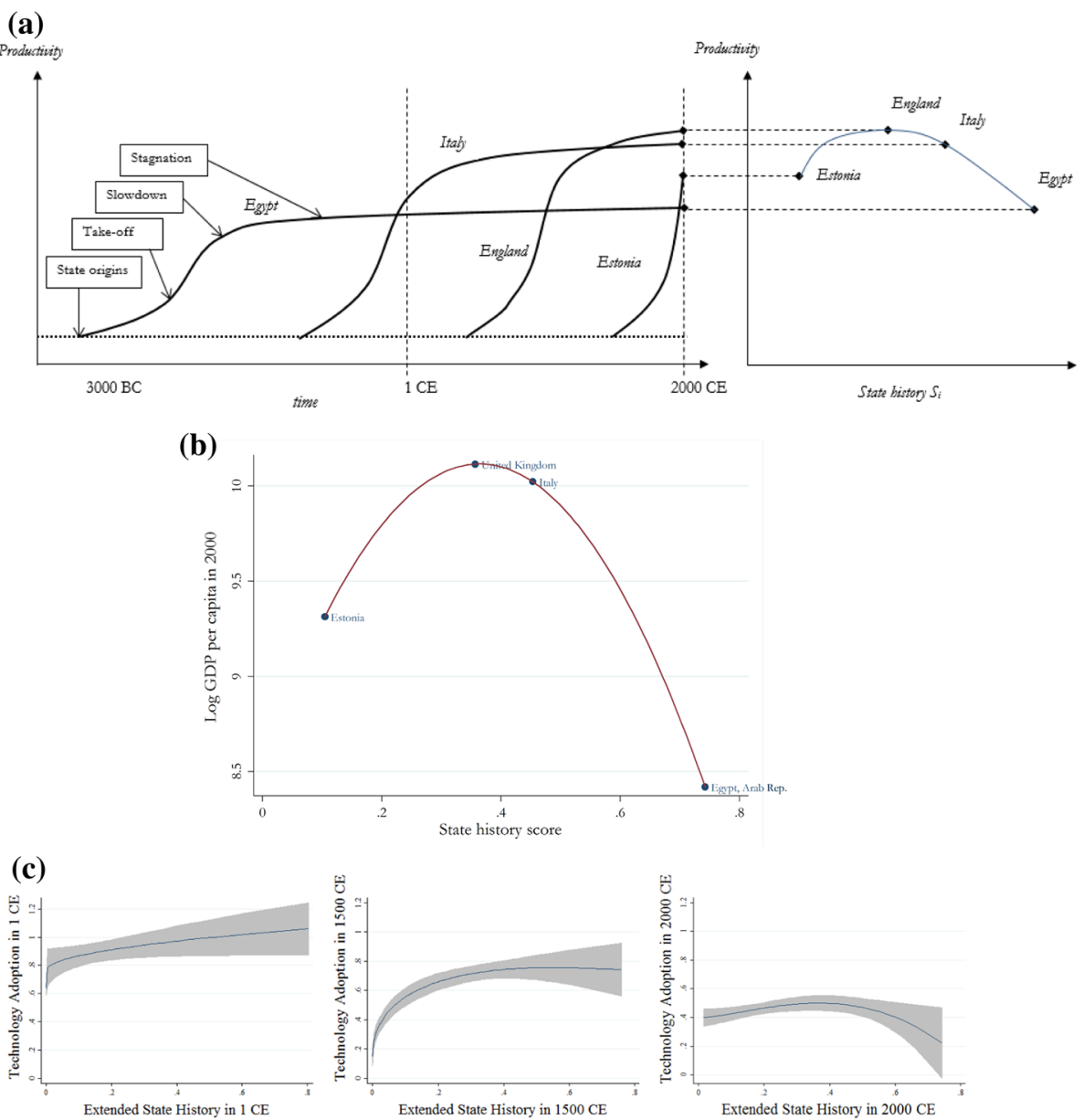

Fig. 1 Predicted pattern of accumulated state history and productivity. a Stylized model and illustrations of long-run state history and economic development. b Relationship between log GDP per capita in 2000 and state history in four illustrative countries. c Relationship between Technology Adoption and Statehist in 1 CE, 1500 $\mathrm{CE}$ and $2000 \mathrm{CE}$ in full cross section of countries. Note: a Shows a stylized model of the long-run relationship between state history and aggregate productivity, using Estonia, England, Italy and Egypt as examples. In the left-hand side of the figure, we explain the typical development over time in the logistic development curves with the four basic states of origins, take-off, slowdown, and eventually stagnation. In the right-hand side of the figure, we map the development of the four states over time into a specific combination of state history scores $S_{i}$ and its corresponding productivity from the left-hand side. b Shows the actual combinations of log GDP per capita in 2000 and the main state history score, using a depreciation rate of $1 \%$, for these four illustrative countries. c Shows the predicted Technology Adoption index from Comin et al. (2010) fitted as a polynomial of extended Statehist, for $1 \mathrm{CE}, 1500 \mathrm{CE}$ and $2000 \mathrm{CE}$ for our full cross-section of countries. The shaded areas are the confidence intervals of the mean. Sources: Data presented below

II. The country did not become fully independent until 1991. The country therefore has a relatively low state history score. Nonetheless, the country has pushed for innovation, such as e-government, and economic growth has been fast since independence with income per capita standing at about $70 \%$ of that of United Kingdom in 2014.

Focusing on the states' age part of state experience, the highly stylized logistic development curves in Fig. 1a only differ along two dimensions: the timing of state emergence 
and the maximum level of attainable development, which increases with every new state. Our argument above proposes that highly centralized governments, typically in the earliest states, in the long run supported less economic dynamism than states where powers were devolved to different institutions. In addition, relative newcomers caught up with and eventually overtook older states. The Romans could learn from experience of Egypt that a state led by a divine regent was inferior to a republican and subsequently imperial order that made better use of human resources, politically and militarily. After $1500 \mathrm{CE}$, England could overtake Italy in part due to its access to trade and colonization opportunities associated with its Atlantic-facing location, but also due to far superior political institutions that strengthened the accountability of government, encouraged commerce, saw the emergence of superior naval and military capabilities, and led to a leading position in the emerging system of international credit. ${ }^{15}$ Our long-run representation implies that Estonia may eventually overtake United Kingdom in productivity when it converges to its long-run maximum level where stagnation ensues. However, like many other countries, Estonia has not yet reached this stage.

To sum up, in Fig. 1a we see that the long-term trend is that the relationship between state experience and productivity is predicted to turn negative among more mature states. This negative relationship arises since newer states reach a higher maximum level of productivity than their older neighboring states. However, due to the fact that many countries are still in a transition period to their long-run steady state level of productivity, there will be a positive-sloping part of the overall contemporary curve as well (the segment between Estonia and England in the figure). Taken together, these opposing trends imply a hump-shaped relationship between state history and contemporary measures of productivity.

In Fig. 1b, we illustrate the consistency with this hypothesis of the pattern of data on accumulated state history and level of GDP per capita in 2000 CE for the four countries discussed above. In line with the prediction, we find that the fitted non-linear curve is indeed hump-shaped with an upward-sloping part between Estonia and United Kingdom and a negative-sloping part to the right. In the empirical section below, we investigate more formally this non-linear relationship in a large cross-section of countries.

It should further be noted that our model actually implies that the relationship between state history and aggregate productivity should change over time. In the year $500 \mathrm{BCE}$, for example, Fig. 1a suggests that Egypt was ahead of Italy, which, in turn, was ahead of England and Estonia in terms of productivity, so that the relationship between state history and productivity at the time should be strictly positive.

As an initial test of our model, we show in Fig. 1c the evolution over time of the relationship between state history and our preferred proxy for productivity (a composite index of technology adoption from Comin et al. 2010) for a cross-section of all countries in the world with available data. When the relationship is estimated early in history, in year $1 \mathrm{CE}$, we find indeed that the fitted non-linear curve has a positive slope, implying that older states (like Egypt) were more technologically advanced at the time. The curve then tilts to become distinctly concave with a short negative-sloping section in $1500 \mathrm{CE}$, with a clear hump-shape emerging in $2000 \mathrm{CE}$. In Figure $\mathrm{C} 1$ in the Appendix, we show that a similar pattern is evident in $1 \mathrm{CE}$ and $1500 \mathrm{CE}$ when we use population density as our proxy for productivity. Our interpretation of this evidence is that it is consistent with the model outlined in Fig. 1a where the disadvantages of being an early state eventually manifest and lead to a gradually stronger negative relationship for older states. ${ }^{16}$

\footnotetext{
15 See Kennedy (1989) for a seminal work on the rise and fall of great Western powers after $1500 \mathrm{CE}$.

16 As Estonia and countries with still younger states, such as New Guinea, develop to their full potential, our model predicts a long-run negative relationship — eventually younger states will be more productive than older
} 
Although Fig. 1a considers the age of states only, other dimensions of state history, such as experience with home-based rule, can also help to account for some countries' laggardness or advance. In some cases, in North Africa and the Middle East, colonization by middle-aged states (e.g British, French) may have generated negative effects on the level of stagnation of earlier developed states. Extractive institutions and other forms of economic domination fuelled by globalization may not only have helped the later comers to overtake earlier states, but may even have influenced the productivity stagnation or decline of the latter. ${ }^{17}$

At the other end of the statehist spectrum, young colonial states, especially those in SubSaharan Africa with no pre-colonial state institutions, have not only had short histories, but also have spent more than half of their macro-political histories under external rule. With modern state structures thrust upon them from without, they could not build institutional capacity organically. This left them vulnerable in the face of post-colonial challenges, against the backdrop of ethnic divisions, over-reliance on natural resources, and a legacy of extractive institutions (Collier 2009). The post-colonial experience highlights that extractive institutions are not exclusively a feature of longer state histories. As a possible consequence, postindependence productivity levels in many countries with young states have declined and income per capita is lower today than in 1960. Thus, while Fig. 1c above suggests that the hump-shaped relationship between state history and aggregate productivity is only transient, other forces at play shed uncertainty over whether and when a globally negative relationship between the two variables will eventually emerge.

Note that if state history before year $1 \mathrm{CE}$ is not counted, as was the case in the statehist index used by Bockstette et al. (2002) and subsequent papers until the present, the state history score for Egypt would be closer to that of Italy. This party explains why analyses based on the data heretofore available tended to find a positive relationship between state history and level of development around the end of the 20th Century (note again the exception of Lagerlöf 2016, discussed above).

\subsection{Towards a growth model}

The stylized pattern above can be translated into a growth theory framework generating specific hypotheses to be tested in the empirical section.

Let $S_{i t}$ be the accumulated state history of a country $i$ at time $t$, where a greater $S_{i t}$ implies that the country has had a more substantial experience of unified, home based, largescale states. For simplicity, we assume that $S_{i t}$ is a positive, linear function of time from the date of state origins onwards. The first state is $i=1$. Thus, the index $i \in\{1,2,3, \ldots\}$

\section{Footnote 16 continued}

over the full range of cases. Such a reversal in relative developmental ranking is strongly related to the findings for the Western world in Olsson and Paik (2013). Of course, the framework ignores the possibility that old states might achieve new vigor by borrowing approaches from younger ones, something that could become more common in a world of declining cultural and informational barriers. We accordingly view assumptions underlying Fig. 1a as useful for organizing historical experience to date, but perhaps not for formulating predictions about the distant future.

17 However, the overall situation in this regard is quite complex and without further analysis we cannot formulate a general conclusion as to whether colonization and economic domination by states of medium age were or were not on balance net contributors to the stagnation of earlier states. For many earlier states colonization was typically either late or never came: Hariri (2012) and Ertan et al. (2016) show that older states (such as China and Turkey) were most likely not to have been colonized by Europeans at all, and Ertan et al. show that if they were colonized (as with what are now the countries of the Levant) it tended to be much later than other countries. Hariri argues that being colonized was advantageous in the sense that it promoted modernization (democratization) of institutions, relative to countries not colonized. 
reflects the historical order of state formation. ${ }^{18}$ We define total factor productivity $A_{i t}$ as a function $A_{i}\left(S_{i t}\right)$ with $\partial A_{i}\left(S_{i t}\right) / \partial S_{i t}>0$, where the positive relationship with state history takes the form of a non-linear, logistic curve as in Fig. 1a. At low levels of $S_{i t}$, aggregate productivity increases sharply with $S_{i t}$ but as state history accumulates, stagnation sets in and $\partial A_{i}\left(S_{i t}, i\right) / \partial S_{i t}$ approaches zero.

We also assume that for any given level of state history $S>0, A_{i}(S)<A_{i+1}(S)$, i.e. of two countries with identical accumulated levels of state history, the state which emerged at later $t$ will be able to attain a higher level of productivity at every level of $S$ and eventually reach a higher maximum productivity. ${ }^{19}$ This advantage stems mainly from the fact that new states could learn from the experiences of older states, or that countries in which the state developed later have been more successful at avoiding the overcentralization of power.

In the preindustrial era, in terms of a standard Malthusian growth model, total output in a territory is given by $Y_{i t}=A_{i t} X_{i}^{\alpha} L_{i t}^{1-\alpha}$ where $Y_{i t}$ is the total output, $X_{i}$ the fixed amount of land in the country, and $L_{i t}$ the level of population (Ashraf and Galor 2011). In a longrun, Malthusian equilibrium, output per capita $Y_{i t} / L_{i t}=y_{i t}$ is constant since any temporary increases in $Y_{i t}$ are offset by higher birth rates, hence population, so that $y_{i t}$ eventually returns to its steady-state level $\overline{y_{i}}$.

Combining the elements above, we can express the Malthusian equilibrium as

$$
\bar{y}_{i}=A_{i}\left(S_{i t}\right) \cdot\left(\frac{X_{i}}{L_{i t}}\right)^{\alpha}=A_{i}\left(S_{i t}\right) \cdot p_{i t}^{-\alpha}
$$

where $p_{i t}=L_{i t} / X_{i}$ is the population density of country $i$ at time $t$. Over the long run, as productivity $A_{i t}$ grows in response to the increase in state experience $S_{i t}$, population density $p_{i t}$ will also increase and country $i$ 's Malthusian equilibrium level of income per capita $\bar{y}_{i}$ will remain intact. When two countries at a given point in time have reached the stagnation level, where $A_{i t}$ is unresponsive to further increases in $S_{i t}$, the level of productivity $A_{i t}$ (as well as the level of population density $p_{i t}$ ) will be relatively lower in the country where states emerged early (with a higher $S_{i t}$ and a lower $i$ ) compared to the country where states emerged later.

There are thus two countervailing effects of extensive state experience on $A_{i t}$ : On the one hand, greater state experience increases the level of productivity within a country directly, up to the steady-state (through fiscal capacity and centralized coordination). But since a higher level of state history also typically implies an early state, its level of productivity is limited compared to countries with later states. This pattern eventually gives rise to the hump-shaped cross-sectional relationship between $A_{i t}$ and $S_{i t}$ some time during the Malthusian era. Note that our model also implies a hump-shaped relationship between $S_{i t}$ and $p_{i t}$. We expect these patterns to emerge by the end of the Malthusian era and therefore, in the empirical section, we test these hypotheses using an index of technology as a proxy for $A_{i t}$ and levels of population density and urbanization rates as our measures of $p_{i t}$ in $1500 \mathrm{CE}$.

In the industrial era, the Malthusian link between productivity levels $A_{i t}$ and levels of population density $p_{i t}$ typically disappears after a period of adjustment. Income levels per capita $Y_{i t} / L_{i t}=y_{i t}$ then tend to be strongly positively correlated with higher levels of $A_{i t}$ (Hall and Jones 1999). For the contemporary era, we will therefore proxy aggregate

\footnotetext{
18 Note that we can assume $S_{i t}<S_{j t}$ for $i<j$ only by adopting the implicit assumption that variation in the territorial coverage, unity, and home based dimensions of our full state history index leave ordering by time of establishment as an adequate approximation. In this subsection, we use state age as shorthand for state experience in its more complete sense for convenience of exposition.

19 Note that this assumption also implies that the logistic curves will attain a more and more steep curvature to the right in Fig. 1a.
} 
productivity by income per capita, which is of course also the standard measure of economic prosperity, and study whether the the historical impact of $S_{i t}$ on $A_{i t}$ prevails even after the transition to modern economies.

\section{Data}

In this section, we outline how the existing index of state history has been extended to cover the BCE period. We will also briefly present some of the key tendencies in the new data series.

\subsection{Constructing the index}

The construction of the index for the BCE period follows the principles developed by Bockstette et al. (2002), applied here to 159 modern-day countries. ${ }^{20}$ We use evidence of written records where available. Where not extant, we rely on archaeological data, following a "diagnostic traits" approach: we consider material manifestations of the monopolization of power, as an "archaeological confirmation of the process of state formation" (Jones and Kautz 1981, pp. 16-17). These can be monumental structures, such as palaces, temples or large urban settlements etc. In the case of Iraq, for instance, there is the transition from small to large urban centers with grand architectural structures such as Uruk in the middle of the 4th millennium BCE. $^{21}$

The second task is to mark the transition from chiefdom to fully-fledged state. Following the paradigm of the evolution of pristine states from chiefdoms (see e.g. Carneiro 1981; Earle 1987; Flannery 1995; Marcus 1992; Spencer 1990; Spencer and Redmond 2004), we mark this distinction in our data by assigning the following values: Band/tribe is marked by a rule score of 0 , paramount chiefdom is assigned 0.75 and fully-fledged state receives the value 1 . Robert Carneiro emphasizes that the paramount chiefdom is the evolutionary link between autonomous bands or tribes and the state. ${ }^{22}$

While it is difficult to know exactly where the chiefdom ends and where the state begins in pre-history, we have made efforts to draw a sensible line where the evidence suggests a noteworthy evolution in socio-political organization. ${ }^{23}$ While this approach is not uncontroversial, it is the most feasible given limited documentary resources. We further detail the assignment of scores in a later section.

For each country, the time of emergence of the first state institutions on its territory is identified, as defined above. State age is defined as the time elapsed from this date until 2000

20 The reader is referred to online Appendix B for a more detailed discussion of the coding procedures and exceptions.

21 Admittedly, the drawback of this "symptomatic" approach is that it blurs the boundary between state and civilization and it is susceptible to misclassifying an emerging or transient civilization into a state in the sense adopted above (see Sect. 2.2).

22 In his definition, the paramount chiefdom is "an autonomous political unit comprising a number of villages or communities under the permanent control of a paramount chief" (Carneiro 1981, p. 45), while the state is "an autonomous political unit, encompassing many communities within its territory and having a centralized government with the power to collect taxes, draft men for work or war, and decree and enforce laws" (Carneiro 1970, p. 733).

23 Such is the case of Mexico, where we assign a score of 0.75 to the period 450-100 BCE for the early urban settlements at Chiapas and Oaxaca. We then raise this score to 1 in $100 \mathrm{BCE}$ when large-scale urban growth at Teotihuacan and the development of previously missing institutions such as a standing army warrant the status of fully-fledged state. 
CE. The oldest state was established on the land of today's Iraq around 3500 BCE. Hence, the time for all countries is divided into 110 periods of 50-years.

For each country $i$ and half century $t$, scores are assigned to reflect three dimensions of state presence, based on the following questions ${ }^{24}$ :

1. Is there a government above the tribal level? Score component $z_{i t}^{1}$ receives 1 point if yes, 0.75 if the government can at best be described as a paramount chiefdom and 0 points if no government is present.

2. Is this government foreign or locally based? $z_{i t}^{2}$ is 1 if the rule is locally based, 0.5 if externally based, and 0.75 for local government with substantial foreign oversight. ${ }^{25}$

3. How much of the territory of the modern country was ruled by this government? $z_{i t}^{3}$ reflects the proportions of the territory under some rule: 1 (over 50\%), 0.75 (25-50\%), $0.5(10-25 \%), 0.3$ (under $10 \%){ }^{26}$

Time is indexed by $t$ and refers to a 50-year period ranging from $t=0$ for 3500-3451 BCE when the first state arose, to $t=109$ for 1951-2000 CE). For every such time interval, we compute a composite State index score by multiplying the three components by one another and by $50^{27}$ :

$$
s_{i t}=z_{i t}^{1} \cdot z_{i t}^{2} \cdot z_{i t}^{3} \cdot 50
$$

Finally, joining the BCE-with the preexisting CE-era series, we aggregate all "flow" scores $s_{i t}$ into Statehist - the comprehensive index of the cumulative state history. ${ }^{28}$ The index is normalized by the score of a hypothetical state with full discounted scores between 3500 $\mathrm{BCE}$ and the period of interest $\tau$ :

$$
S_{i \tau}=\frac{\sum_{t=0}^{\tau}(1+\rho)^{t-\tau} \cdot s_{i t}}{\sum_{t=0}^{\tau}(1+\rho)^{t-\tau} \cdot 50}
$$

This cumulative Statehist index $S_{i \tau}$ ranges from 0 to 1 and can be calculated at virtually any point in history $\tau=\{0,1, \ldots 109\}$. We calculate it mainly for $1500 \mathrm{CE}$ (at $\tau=99$ ) and for $2000 \mathrm{CE}$, usually discounting the more distant past relative to the present by setting $\rho>0$, although usually at a modest value. For instance, the Statehist value of a state with full scores discounted at $1 \%$ between $3500 \mathrm{BCE}$ and $2000 \mathrm{CE}$ is 3359.79 . The previous literature has employed $\rho=0.05$, in light of the reasonable assumption that the more distant past matters less today than recent history. With the additional data, however, this rate gives almost no

24 Each dimension is denoted by $z_{i t}^{c}$, which is the score for component $c$ in country $i$ for period $t$.

25 If there were multiple polities within a present country's borders, its state score for the period is coded as a simple average of their respective scores.

26 For multiple contemporaneous states within what is now a single country $z_{i t}^{3}$ is adjusted down one category, because centralized coordination is assumed to decrease.

27 Half century periods are used in order to simplify value assignments for the large number of case-period units in which there is either no known state or available information imprecisely dated. This periodization affects the index's construction when there is detailed information only insofar as the time discounting procedure discussed below is applied to half centuries. Within period changes in $z_{i t}^{c}$ require averaging the scores over subperiods, using as weights the number of years in each sub-period $\theta$ divided by 50 :

$$
s_{i t}=50 \cdot\left[\left(z_{i t 1}^{1} \cdot z_{i t 1}^{2} \cdot z_{i t 1}^{3}\right) \cdot w_{i t 1}+\left(z_{i t 2}^{1} \cdot z_{i t 2}^{2} \cdot z_{i t 2}^{3}\right) \cdot w_{i t 2}+\cdots\right] .
$$

28 Some minor adjustments were made to the years 1-1950 CE data of a few countries, but the correlation with the initial index, considering year 1 to $1950 \mathrm{CE}$ periods only, is $99 \%$. 
weight to the long stream of $s_{i t}$-scores before $1 \mathrm{CE}{ }^{29}$ While it of course remains to be seen below just how useful placing weight on the distant past will be, our convention is to employ the $1 \%$ discount factor when calculating the normalized Statehist score. ${ }^{30}$

To answer the three questions (a-c) above in a manner that is consistent across periods, we relied mainly on information in the Encyclopedia Britannica Online, but also additional sources where information in Britannica was insufficient. We provide additional detail on our data sources and illustrate the coding process and further data aggregations in online Appendix B. Accompanying this paper is also an online Data Coding Appendix, which provides a comprehensive list of coding decisions for all country-period observations.

\subsection{A brief look at the data}

In this section we present some patterns that arise from the complete state history time series and the data used in forthcoming analyses.

Firstly, we note that the evolution of state institutions in the world follows approximately an exponential upward trend with periods of rapid growth punctuated by periods of stagnation (Fig. 2). The graph shows the log of the aggregated percentage score for all contemporary countries in our sample on the vertical axis plotted against number of years BCE or CE on the horizontal axis. The percentage score in period $t$ is calculated as State index world $(t)=100 \cdot \sum_{i=1}^{N} s_{i t} /(N \cdot 50)$ where $N=159$ is the number of included countries and where $s_{i t} \in[0,50]$ is the state history score for country $i$ during 50-year interval $t$, as described above. ${ }^{31}$ A value close to $0 \%$ in this world index indicates that there is almost no sign of state presence in any of the included countries in period $t$ whereas a score of 100 means that all 159 countries reach the maximum value $s_{i t}=50$ in our state measure during that period. ${ }^{32}$

Several periods are characterized by rapid state evolution whereas other periods are marked by a general decline. The first boom in state emergence appears already in 3500-2300 BCE, which then ends with a long period of stagnation. The other major stagnations in the figure happened around $1750 \mathrm{BCE}, 1200 \mathrm{BCE}$, and $400 \mathrm{CE}$. A second period of rapid growth was $850 \mathrm{BCE}-1 \mathrm{CE}$ during the Iron Age. From just after the collapse of the Roman empire around $450 \mathrm{CE}$, aggregate state emergence shows a steady upward trend.

This pattern is also visible in Fig. 3, which in addition shows the regional aggregated percentage score for all contemporary countries in our sample (this figure displays world and regional averages of the State index, rather than the natural log of that average as in Fig. 2, allowing the reader to get a sense of the trend in a form some may find more intuitive). We disaggregate the evolution of state history into the four main agricultural core areas: Western,

29 The 5\% discounted extended Statehist score (for the 3500 BCE to 2000 CE period) has a correlation of up to $99.3 \%$ with the $5 \%$ discounted 1-1950 CE score.

30 The $1 \%$ discounted (extended) Statehist index at $2000 \mathrm{CE}$ (covering the full period beginning from 3500 $\mathrm{BCE}$ ) has a 0.93 correlation with the 1-1950 CE $1 \%$ discounted Statehist index and 0.89 correlation with the $1-1950$ CE $5 \%$ discounted Statehist index. We do, however, use the 0.1 and $2 \%$ discounted index in alternative estimations, as reported below in Sect. 5.

31 Note that State index world $(t)$ describes the "flow" level of state development in the world in period $t$ and not the cumulative "stock" of state experience.

32 Since many modern-day countries did not have full states in the spirit of our definition during the entirety of the last time period 1951-2000, the aggregate percentage in the graph is about $88 \%$ at the end of the time series. Many states were de-colonized part way through the period, a number emerged from the Soviet Union and Yugoslavia (and thus lack home-based governments until the 1990s, following our conventions), others experienced contending governments or state failure, etc. 


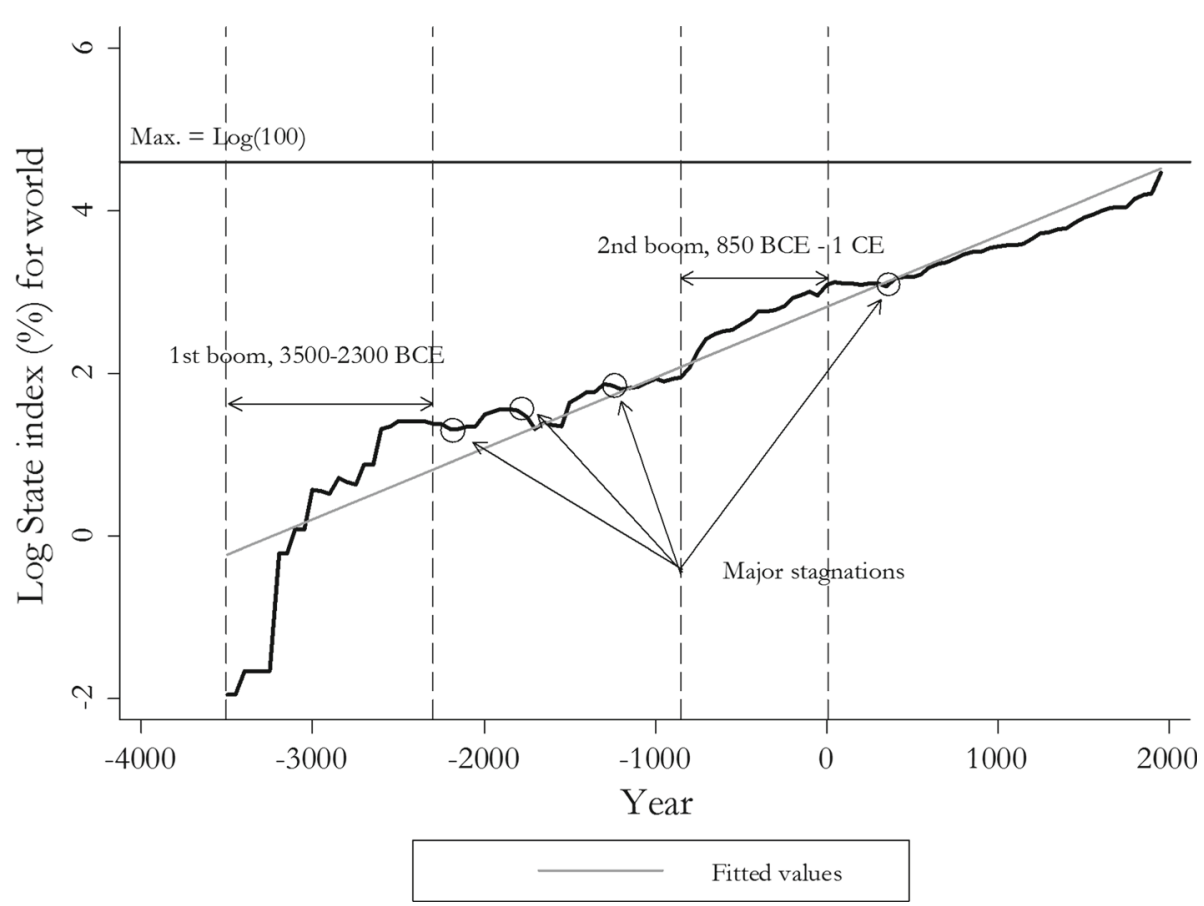

Fig. 2 Emergence of states in the world 3500 BCE-2000 CE. Note: The graph shows the logged value of the aggregate State index for 159 countries identified during 110 50-year intervals between $3500 \mathrm{BCE}$ and 2000 CE. The value 100 would signify all 159 countries in our sample are full states, as defined in our text, including high geographical extent and unity and being entirely locally based. On the horizontal axis, negative values imply years BCE whereas positive values show the CE period. A linear fitted regression line has been included. The State index is calculated as described in the text

Eastern Asia, Sub-Saharan Africa, and the Americas. ${ }^{33}$ These four areas are created on the basis of how Neolithic agriculture and civilization spread during early historical times.

When we divide up the world in this way, some striking historical differences between the regions appear: State evolution started earliest in the Western area, with Eastern Asia lagging behind until rough convergence (indeed, initially overtaking) around $500 \mathrm{CE}$, with the other regions gaining steam later and all converging only toward the end of the era of European colonialism. State emergence was earliest in Eastern Asia and in the Western region. Interestingly, both of these early civilizations took off on a more rapid path after 850 BCE. By the time of the Western Roman collapse after $450 \mathrm{CE}$, Asian state development overtakes the Western one for the first time. ${ }^{34}$

The other two regions, the Americas and Sub-Saharan Africa, clearly lag behind, particularly after the Eurasian turning point $850 \mathrm{BCE}$. From about $500 \mathrm{CE}$, the pace of state emergence starts to rise in Sub-Saharan Africa. When the colonial era starts in the late 15 th century $\mathrm{CE}$, the lagging regions experience a dramatic increase in the State index. This increase is of course to a great extent driven by the emergence of colonial states, created by

33 The division into agricultural core areas follows the practice in Morris (2010) and Olsson and Paik (2013) (see also Diamond and Bellwood 2003). Combining the two or three distinct agricultural cores of the Americas identified by some writers is a convenient simplification.

34 See Morris (2010) for a detailed comparative analysis of Western and Eastern history since the Neolithic. 


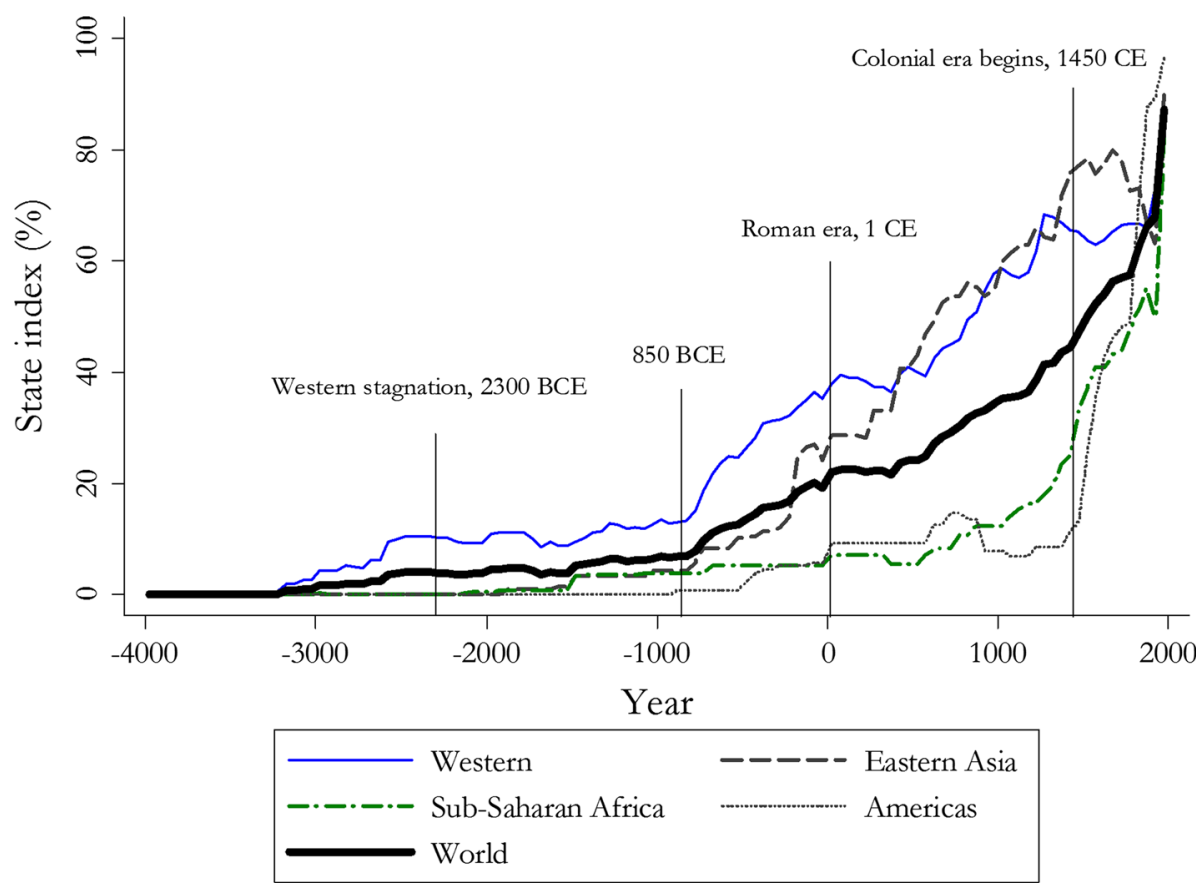

Fig. 3 Emergence of states in four agricultural core areas and in the world as a whole 3500 BCE-2000 CE. Note: The figure shows the development of the aggregated State index in the Western agricultural zone (including 62 current countries in Europe, North Africa, the Middle East, as well as Afghanistan, Armenia, Azerbaijan, Georgia, India, Iran, Kazakhstan, Kyrgyzstan, Pakistan, Russia, Tajikistan, Turkmenistan, Uzbekistan), Eastern Asia (20 countries), Americas (including 27 countries in North and South America and in the Caribbean), and Sub-Saharan Africa (47 countries). Oceania (only 3 countries in our sample) is omitted. It also shows the aggregate index for the 159 countries in the world as a whole (solid black line). On the horizontal axis, negative values imply years BCE whereas positive values show the CE period. Particular years with trend breaks are marked

European powers (although $z^{2}$ is capped at 0.5 so long as colonial status continues). By the final period of observation (1951-2000), the Americas has the highest score on state presence among all regions in the world. ${ }^{35}$

The Statehist index and other variables related to state experience, as well as outcomes and control variables used in all forthcoming analyses are summarized in Table 1 below. Full definitions of each variable are given in the online Appendix.

\section{State history and economic development}

We now proceed to analyze the relationship between state history and different indicators for historical and contemporary levels of productivity. Our proxies for aggregate productivity will be an index of technology adoption, population density, rates of urbanization, and GDP per capita.

\footnotetext{
35 In Figure C2 of the online Appendix, we zoom in on the last 550 years of state history and show trends for Western Offshoots including the U.S. and Canada (along with Australia and New Zealand) and for the rest of the Americas (Latin America and the Caribbean). The latter two regions are shown to come from behind to overtake even Europe in internally controlled state presence by the mid-1800s.
} 
Table 1 Summary statistics

\begin{tabular}{|c|c|c|c|c|c|}
\hline & $\mathrm{N}$ & Mean & SD & Min & $\operatorname{Max}$ \\
\hline \multicolumn{6}{|l|}{ Panel A: State history indicators } \\
\hline Statehist & 159 & 0.234 & 0.172 & 0.017 & 0.743 \\
\hline Statehist $1-1950 \mathrm{CE}$ & 159 & 0.386 & 0.261 & 0.012 & 0.978 \\
\hline Statehist in $1500 \mathrm{CE}$ & 159 & 0.171 & 0.183 & 0.000 & 0.760 \\
\hline Ancestry-Adjusted Statehist of $1500 \mathrm{CE}$ & 152 & 0.221 & 0.166 & 0.000 & 0.747 \\
\hline State age (millennia) & 159 & 1.640 & 1.430 & 0.100 & 5.500 \\
\hline Internally-originated & 159 & 0.491 & 0.501 & 0.000 & 1.000 \\
\hline \multicolumn{6}{|l|}{ Panel B: Outcome variables } \\
\hline Technology adoption in $1500 \mathrm{CE}$ & 112 & 0.487 & 0.317 & 0.000 & 1.000 \\
\hline (Log) Population density in $1500 \mathrm{CE}$ & 154 & 0.905 & 1.461 & -3.817 & 3.842 \\
\hline Urbanization rate in $1500 \mathrm{CE}$ & 83 & 7.278 & 5.134 & 0.000 & 28.000 \\
\hline Technology adoption in $2000 \mathrm{CE}$ & 130 & 0.451 & 0.198 & 0.174 & 1.012 \\
\hline$(\mathrm{Log}) \mathrm{GDP} p \mathrm{p}$ in $2000 \mathrm{CE}$ & 154 & 7.488 & 1.606 & 4.463 & 10.531 \\
\hline \multicolumn{6}{|l|}{ Panel C: Covariates } \\
\hline Agyears: $2000 \mathrm{CE}-$ neolithic transition & 151 & 4.717 & 2.442 & 0.362 & 10.500 \\
\hline Origtime: $2000 \mathrm{CE} \_$first human settlement & 158 & 58.917 & 49.958 & 0.200 & 160.000 \\
\hline Absolute centroid latitude & 159 & 26.369 & 17.704 & 0.422 & 67.470 \\
\hline Distance to coast and rivers & 149 & 347.334 & 457.408 & 7.952 & 2385.580 \\
\hline Landlocked & 134 & 0.224 & 0.418 & 0.000 & 1.000 \\
\hline Mean elevation & 149 & 637.715 & 551.281 & 9.167 & 3185.920 \\
\hline Land suitability & 145 & 0.378 & 0.248 & 0.000 & 0.960 \\
\hline Percentage arable land & 156 & 15.852 & 14.001 & 0.040 & 62.100 \\
\hline Temperature & 158 & 18.226 & 8.350 & -7.929 & 28.639 \\
\hline Precipitation & 158 & 92.959 & 61.700 & 2.911 & 259.952 \\
\hline Malaria (percentage population at risk) & 151 & 0.316 & 0.426 & 0.000 & 1.000 \\
\hline
\end{tabular}

The table summarizes all variables used in the analysis, as follows: (1) Panel A describes the State history variables created by us. Note that Ancestry-Adjusted Statehist of 1500 is the average accumulated state history to $1500 \mathrm{CE}$ of the year 1500 ancestors (by territory of residence at that time) of the year 2000 population of each country; (2) Panel B outlines some historical and economic variables which are used as dependent variables in the regression analysis. The data for historical population density is based on population data from McEvedy and Jones (1978) and land data from World Bank World Development Indicators. The data for urbanization rate in $1 \mathrm{CE}$ is taken from Comin et al. (2010) and is based on Peregrine (2003). The data for urbanization rate in $1500 \mathrm{CE}$ is that reported by Acemoglu et al. (2005). The Average Technology Adoption indices in $1 \mathrm{CE}, 1500$ $\mathrm{CE}$ and $2000 \mathrm{CE}$ are constructed by Comin et al. (2010). Per capita GDP is expressed in current US dollars, as provided by the World Bank; (3) Panel $\mathrm{C}$ details the covariates included in the regressions. Agyears was assembled by Putterman and Trainor (2006) and it records the number of millennia elapsed in 2000 CE since the Neolithic transition took place. Origtime was coded by Ahlerup and Olsson (2012) and it represents the time in millennia since initial uninterrupted settlement by modern humans (before $2000 \mathrm{CE}$ ). The geographic and climatic controls are retrieved from various sources. The variables' construction is detailed in the online Appendix A 


\subsection{State history and pre-industrial economic development}

\section{State history and productivity in $1500 \mathrm{CE}$}

We begin with the empirical question of the relationship between state history and productivity in the Malthusian era. The key predicted pattern in Fig. 1a was a hump-shaped relationship between our state history measure and aggregate productivity in a cross-section of countries, reflecting on the one hand that newer or more inexperienced states tend to be in the process of converging to their own maximum productivity potential, whereas more experienced states already have attained a relatively low maximum level. Was such a tendency in place already in $1500 \mathrm{CE}$ ?

As a starting point, we proxy historical productivity with the average index of technology adoption constructed by Comin et al. (2010). Using various data sources on the presence and complexity of various technologies, the country-level index captures advances in five sectors: agriculture, transportation, communications, writing, and military. The index is computed for $1500 \mathrm{CE}$ and $2000 \mathrm{CE}$, using slightly different approaches, which we describe in some detail in online Appendix A.

In order to test this prediction, we set up the following model:

$$
\text { Technology } 1500_{i}=\beta_{0}+\beta_{1} \cdot \text { Statehist } 1500_{i}+\beta_{2} \cdot \text { Statehist } 1500_{i}^{2}+\epsilon_{i}
$$

On the left hand-side of Eq. (4) we have the average technology adoption index in $1500 \mathrm{CE}$. On the right-hand side we include our main independent variable, Statehist (the cumulative index shown in Eq. (3) accumulated in $1500 \mathrm{CE}$ ), both linear and squared, to allow for a quadratic relationship. The Statehist index is normalized with respect to 3500 BCE-1500 $\mathrm{CE}$ and computed using a $1 \%$ discount rate per period. This equation captures the potentially hump-shaped relationship to Statehist across countries. We also consider variants of (4) that include additional controls, represented by:

Technology $1500_{i}=\beta_{0}+\beta_{1} \cdot$ Statehist $1500_{i}+\beta_{2} \cdot$ Statehist $1500_{i}^{2}+\beta_{j}^{\prime} \cdot Z_{i}+\beta_{k}^{\prime} \cdot X_{i}+\lambda_{c}+\epsilon_{i}$

$Z_{i}$ is a vector of historical controls including: $\operatorname{Agyears}_{i}$, the time before present since the transition to agriculture in the country in question, a variable taken from Putterman and Trainor (2006); Origtime $_{i}$ - the approximate time since the first settlement on the territory of the modern-day country by anatomically modern humans, a variable introduced by Ahlerup and Olsson (2012) as a determinant of the variation in levels of ethnic diversity across the world. In a more flexible specification, we include the square of Origtime $_{i}$ in order to account for recent developments in the literature postulating that the patterns of human settlement in prehistory may have nonlinear effects on later economic development (Ashraf and Galor 2013). In the same specification we also include State age $e_{i}$ in $1500 \mathrm{CE}$ (the time elapsed in $1500 \mathrm{CE}$ from the date of state emergence). $X_{i}$ is a vector containing geographic controls. These include: the absolute latitude of the centroid of the modern-day country $i$, whether the country is landlocked, its distance to coast or ocean-navigable river, average elevation, land suitability for agriculture, climatic variables for temperature and precipitation, and the risk of malaria. ${ }^{36} \lambda_{c}$ is a vector of continent fixed effects. The results are displayed in Table 2. Columns (1) and (2) present linear and quadratic versions of Eq. (4), while columns (3)-(7) add further controls, as in Eq. (5).

\footnotetext{
36 These variables are taken from the Portland Physical Geography dataset and from the dataset compiled from various other sources by Ashraf and Galor (2013). See the online Appendix A for more details on variables' construction and collection.
} 
Table 2 State history and average technology adoption in $1500 \mathrm{CE}$

\begin{tabular}{|c|c|c|c|c|c|c|c|}
\hline & \multicolumn{7}{|c|}{ Technology adoption in $1500 \mathrm{CE}$} \\
\hline & (1) & (2) & (3) & (4) & $(5)$ & (6) & (7) \\
\hline $\begin{array}{c}\text { Statehist in } \\
1500 \mathrm{CE}\end{array}$ & $\begin{array}{l}1.152^{* * * *} \\
(0.118)\end{array}$ & $\begin{array}{l}2.643 * * * \\
(0.328)\end{array}$ & & $\begin{array}{l}1.809 * * * \\
(0.399)\end{array}$ & $\begin{array}{l}1.535 * * * \\
(0.306)\end{array}$ & $\begin{array}{l}0.811 * * * \\
(0.198)\end{array}$ & $\begin{array}{l}1.168 * * * \\
(0.275)\end{array}$ \\
\hline $\begin{array}{c}\text { Statehist in } \\
1500 \mathrm{CE} \\
\text { squared }\end{array}$ & & $\begin{array}{l}-2.993 * * * \\
(0.645)\end{array}$ & & $\begin{array}{l}-2.585^{* * * *} \\
(0.744)\end{array}$ & $\begin{array}{l}-1.501^{* * *} \\
(0.543)\end{array}$ & $\begin{array}{l}-0.340 \\
(0.330)\end{array}$ & $\begin{array}{l}-0.226 \\
(0.306)\end{array}$ \\
\hline $\begin{array}{c}\text { Agyears in } \\
1500 \mathrm{CE}\end{array}$ & & & $\begin{array}{l}0.104 * * * \\
(0.008)\end{array}$ & $\begin{array}{l}0.068 * * * \\
(0.014)\end{array}$ & $\begin{array}{l}0.038^{* * *} \\
(0.012)\end{array}$ & $\begin{array}{l}0.005 \\
(0.010)\end{array}$ & $\begin{array}{l}0.013 \\
(0.011)\end{array}$ \\
\hline $\begin{array}{c}\text { Origtime in } \\
1500 \mathrm{CE}\end{array}$ & & & & & $\begin{array}{l}0.001 \\
(0.001)\end{array}$ & $\begin{array}{l}-0.001^{* *} \\
(0.001)\end{array}$ & $\begin{array}{l}0.000 \\
(0.001)\end{array}$ \\
\hline $\begin{array}{l}\text { Origtime in } \\
1500 \mathrm{CE} \\
\text { squared }\end{array}$ & & & & & & & $\begin{array}{l}-0.000 \\
(0.000)\end{array}$ \\
\hline $\begin{array}{l}\text { State age in } \\
1500 \mathrm{CE}\end{array}$ & & & & & & & $\begin{array}{l}-0.075^{*} \\
(0.043)\end{array}$ \\
\hline Observations & 112 & 112 & 110 & 110 & 107 & 107 & 107 \\
\hline R-squared & 0.446 & 0.558 & 0.532 & 0.641 & 0.818 & 0.904 & 0.912 \\
\hline Controls & No & No & No & No & Yes & Yes & Yes \\
\hline Continent FE & No & No & No & No & No & Yes & Yes \\
\hline
\end{tabular}

The table displays OLS estimates from regressions of average technology adoption in $1500 \mathrm{CE}$ on the extended Statehist of 1500 CE, linear and squared. The Average Technology Adoption index in $1500 \mathrm{CE}$ is constructed by Comin et al. (2010). The list of controls includes: absolute latitude, an indicator of whether the present-day country is landlocked, distance to coast and rivers, mean elevation, land suitability, percentage arable land, temperature, precipitation, percentage population at risk of contracting malaria. Robust standard errors in parentheses

$* * * p<0.01, * * p<0.05, * p<0.1$

In column (1) we display the simple association between technology adoption and Statehist, which is positive and significant. In column (2), where we add Statehist squared, our main coefficients of interest, $\beta_{1}$ and $\beta_{2}$, display a concave pattern: $\beta_{1}$ is positive, while $\beta_{2}$ is negative, both significant at $1 \%$. In the online Appendix Table D1, we estimate this specification using Statehist discounted by alternative factors, $0.1 \%$ and $2 \%$, which reveal the qualitatively identical result of significant concavity. As concavity does not imply non-monotonicity, to test for the latter, we run piece-wise estimations using the linear Statehist separately in countries below and above the technology-maximizing level of Statehist implied from Eq. (4) (which is 0.44 , with only 9 countries recording a higher Statehist of $1500 C E$ ). ${ }^{37}$ The results reported for different Statehist discount rates in the online Appendix Table D2, including our main case $1 \%$ rate, show positive insignificant slopes above the maximizing Statehist. Therefore, we do not find an inverse-u shape in the case of technology adoption in $1500 \mathrm{CE}$.

In column (4) we add to the model the first historical control - Agyears (shown to be positively significantly correlated with the dependent variable in column 3 , for comparison purposes). Its inclusion only slightly changes the signs and the magnitude of the coefficients of the Statehist terms. Moreover, the effect of the time from transition to agriculture is reduced relative to column (3). When we also add Origtime and geographical controls in column (5), the magnitude of the estimates changes slightly, but the relationship remains concave.

37 We thank an anonymous reviewer for suggesting this method of testing whether our estimated humpshaped relationships have rising and falling portions. This method with wide applications in social sciences, is proposed and discussed in Simonsohn (2016). 
The continent fixed effects in the last two columns reduce the squared term's coefficient, which becomes insignificant. ${ }^{38}$

\section{State history, population and urbanization in $1500 \mathrm{CE}$}

We now inquire whether this concave pattern is reflected in other commonly used indicators of historical productivity: population density (Table 3, panel A) and urbanization rate in 1500 CE (Table 3, panel B). All specifications are analogous to those in Table 2.

The extended Statehist is positively and significantly correlated with past population density and urbanization (column 1). Column 2 shows, however, that a quadratic relationship fits the data even better, with both linear and square terms obtaining highly significant estimated coefficients (the same holds when using discounts of $0.1 \%$ of $2 \%$, as Appendix Table D3 shows). The population density maximizing level of Statehist is that of Greece (around 0.42). For population density, the below/above maximum regressions including only linear Statehist (Appendix Table D4) display negative slopes above the maximizing value of Statehist, significant when we use a $2 \%$ discount rate for Statehist. Hence, some evidence indicates an inverse-u shape already forming in $1500 \mathrm{CE}$ (albeit not when we look at urbanization, which is maximized by a Statehist value of 0.64 , which is above the range represented in the data). Both for population density and urbanization, quadratic yet monotonic patterns emerge in the specifications which introduce controls and continent fixed effects. In conclusion, while there are clear signs of diminishing benefits of additional state experience as of $1500 \mathrm{CE}$, there are few indications that added state experience was a net liability for more experienced states as of that year. ${ }^{39}$

\subsection{State history and current economic development}

In our theoretical framework, the downward sloping portion of the cross-country Fig. 1a was assumed to result from less experienced states overtaking more experienced ones. The other portion may be explained by the many states in several parts of the world which emerged only in recent centuries. Thus, we expect contemporary levels of development to correlate in a non-monotonic fashion with accumulated Statehist. To investigate this, we estimate the model with technology adoption and GDP per capita in $2000 \mathrm{CE}$ as a quadratic function of state history. The results are displayed in Tables 4,5 and 6 below.

However, when analyzing the current levels of technological sophistication or output, using the raw Statehist data means that we only account for the history within the territories of present-day countries. This ignores the state history of other territories from which people migrated in recent centuries to settle in new territories. Population flows after 1500, when the era of colonization began, are instrumental in mapping the impact of historical events to today's economic performance. This is because the ancestors of today's population have evidently brought with them the history, the know-how and the experience with state insti-

\footnotetext{
38 We also fitted similar regression models where technology adoption and Statehist correspond to year 1 CE. The results in Table D14 display some evidence of a concave, albeit less robust relationship between Statehist and technology adoption, as the coefficients are reduced in magnitude and become insignificant when controlling for the time since the transition to agriculture. As a robustness check, we have also redone the estimations for $1500 \mathrm{CE}$ and $1 \mathrm{CE}$ using the overall technology adoption index excluding the agriculture components; the results for $1500 \mathrm{CE}$ are very similar to those in Table 2, and they display a significant quadratic relationship in the most complete specifications for 1 CE (see Table D15 in the Appendix).

39 We also fitted similar regression models where these economic outcomes correspond to year $1 \mathrm{CE}$, and depend on Statehist up to that year, linear and squared. The results displayed in Table D16 display some evidence of a concave relationship between Statehist and historical economic outcomes, but one that is less robust in $1 \mathrm{CE}$ than in $1500 \mathrm{CE}$, because the coefficients are reduced in magnitude and become insignificant when controlling for the time since the transition to agriculture.
} 
tutions from their places of origin (Putterman and Weil 2010; Comin et al. 2010; Ashraf and Galor 2013).

We therefore also use an alternative measure of state history which is obtained by adjusting the $1500 \mathrm{CE}$ Statehist index with the migration matrix developed by Putterman and Weil (2010). We then re-estimate our model using this new measure-the ancestry-adjusted Statehist-which, for each country, represents the average pre-industrial Statehist of its year 2000 population's ancestors, with the weights for each source country being the share of then-living ancestors estimated to have lived on its present-day territory. These alternative results are displayed in Tables 4, panel B and 6.

Technology adoption in 2000 CE displays a similar concave relationship with year 2000 Statehist as did the technology index of year 1500 CE (Table 4, panel A). Furthermore, using the ancestry-adjusted Statehist in $1500 \mathrm{CE}$ to explain the differences in average technology adoption in 2000 yields robustly significant estimates across all specifications, with larger magnitudes and higher R-squared statistics than when using the Statehist in 2000 CE. This result is consistent with our theoretical expectation that the relationship between technology and state experience was concave in the late Malthusian era, and that it was transmitted all the way into modern-day levels of technology adoption. The unconditional relationship shown in column (2) of Table 4, panel B, withstands using different discount rates for Statehist, and the relationship exhibits the downward sloping portion of an inverted-u shape in regressions with a linear Statehist above and below its implied maximizing value (panel B in Tables D5-D8). ${ }^{40}$

Given the central role of aggregate productivity in the standard production functions for total output, we argue the hump-shape should also emerge when we look at GDP. Figure 4 illustrates the essence of our findings. On the Y-axis we have the logarithm of GDP per capita in 2000 and on the $\mathrm{X}$-axis we have the extended Statehist (normalized with respect to 3500 BCE-2000 CE and computed using a 1\% discount rate per period).

The figure displays a scatter plot of all countries in the sample, while also allowing for a quadratic fit of the relationship between output and Statehist. The hump-shaped relationship emerges when using the extended Statehist. ${ }^{41}$ In the online Appendix Figure C3, we show that the state history index based on 1-1950 CE data does not display the downward sloping portion seen in Fig. 4.

We estimate the quadratic relationship to the logarithm of GDP per capita in $2000 \mathrm{CE}$ in Table 5, panel A. In panel B, the Statehist 1-1950 CE data are used for purposes of comparison. All specifications are analogous to the ones in the previous tables.

As before, the simple correlation between per capita income and Statehist (column 1) is positive and similar in magnitude across the two panels, but slightly less precisely estimated when the independent variable is the extended Statehist. In column (2) we add the squared Statehist, and the results mirror the pattern in Fig. 4: In panel A, both coefficients are significant at $1 \%$, and their signs confirm the concave relationship between log per capita GDP and state history. By contrast, in panel B, the counterpart of this specification using Statehist

\footnotetext{
40 In the mentioned appendix tables, that is, we check that the concavity of the quadratic form in Table 4 has significant upward and downward sloping portions by splitting the sample at the implied maximum of the dependent variable with respect to Statehist, and estimating regressions using only the linear Statehist term for the samples to the left and right of that maximum. Significant estimated coefficients on that term are taken as confirmation that the concavity of the quadratic form entails both upward and downward sloping portions. 41 This quadratic relationship is also suggested by the scatter plots displayed separately for internally- and externally- originated states (i.e. the rule in the first ever state or paramount chiefdom on a certain territory was imposed from within that territory and from without, respectively) and when we use the ancestry-adjusted Statehist index. See Figures C4-C6 in the Appendix.
} 


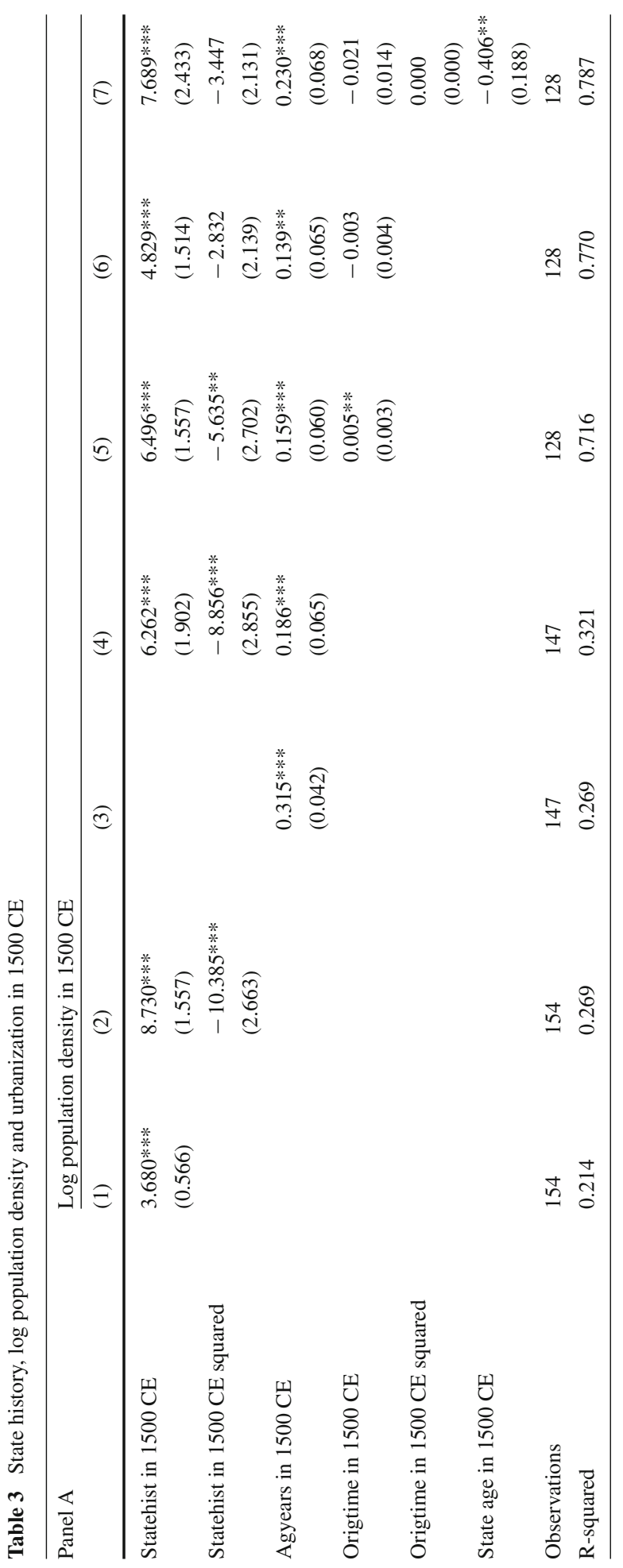

\section{照 Springer}




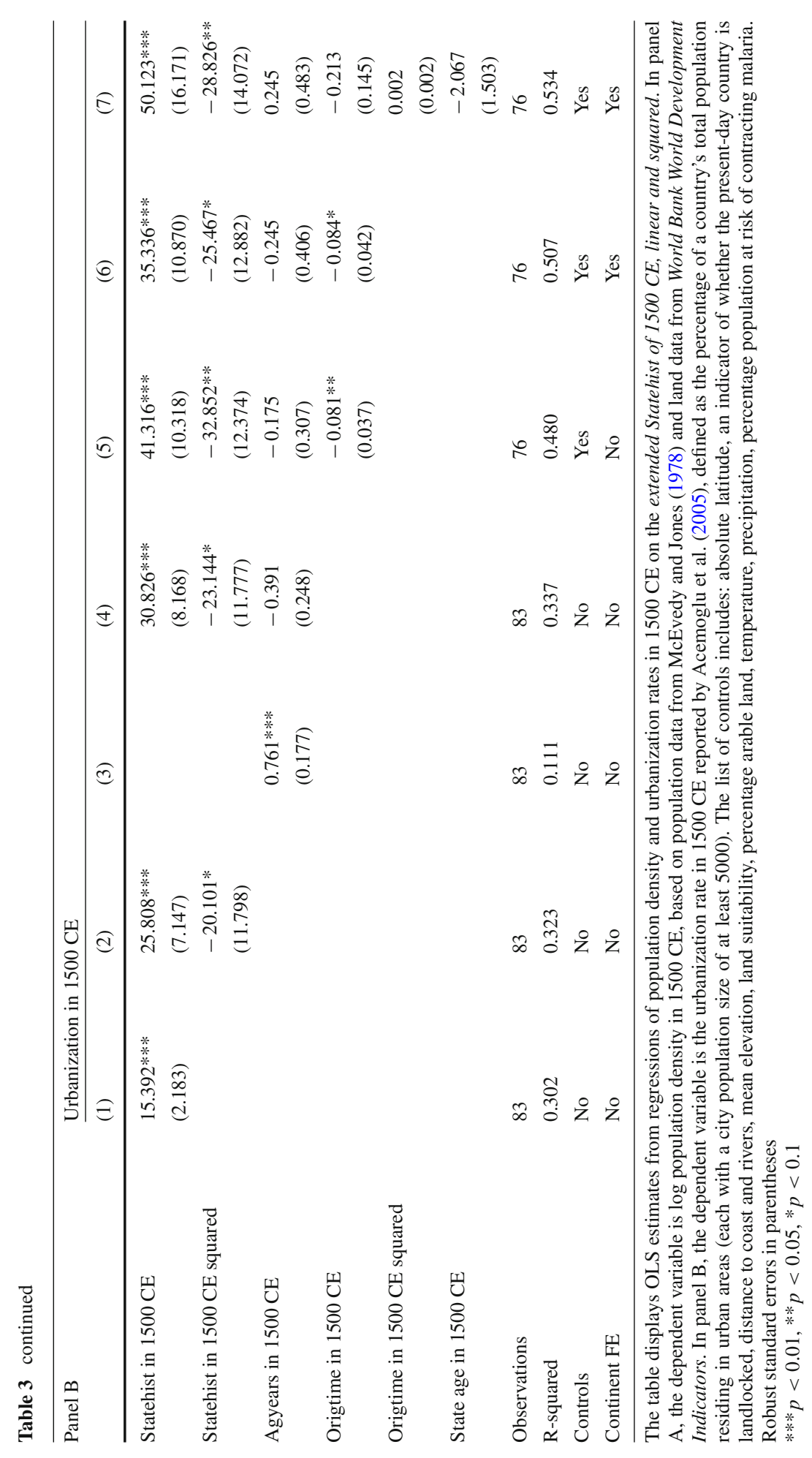




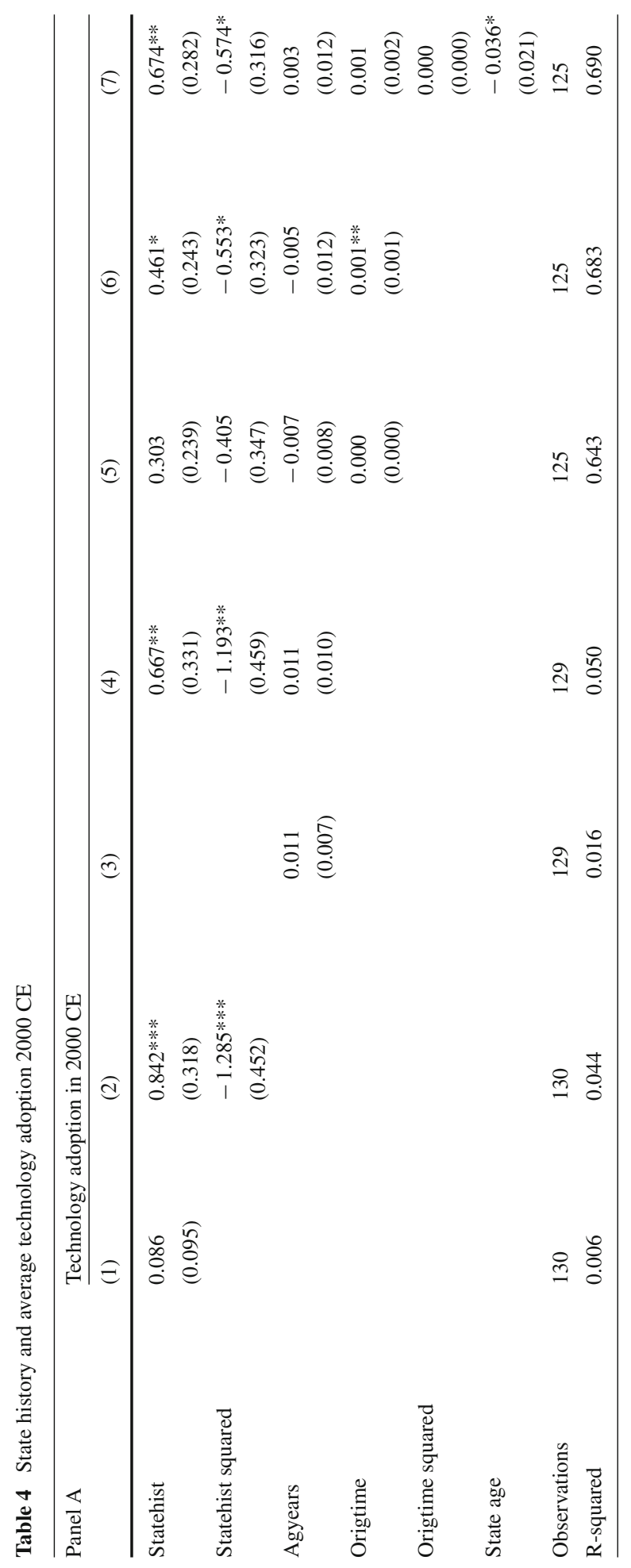




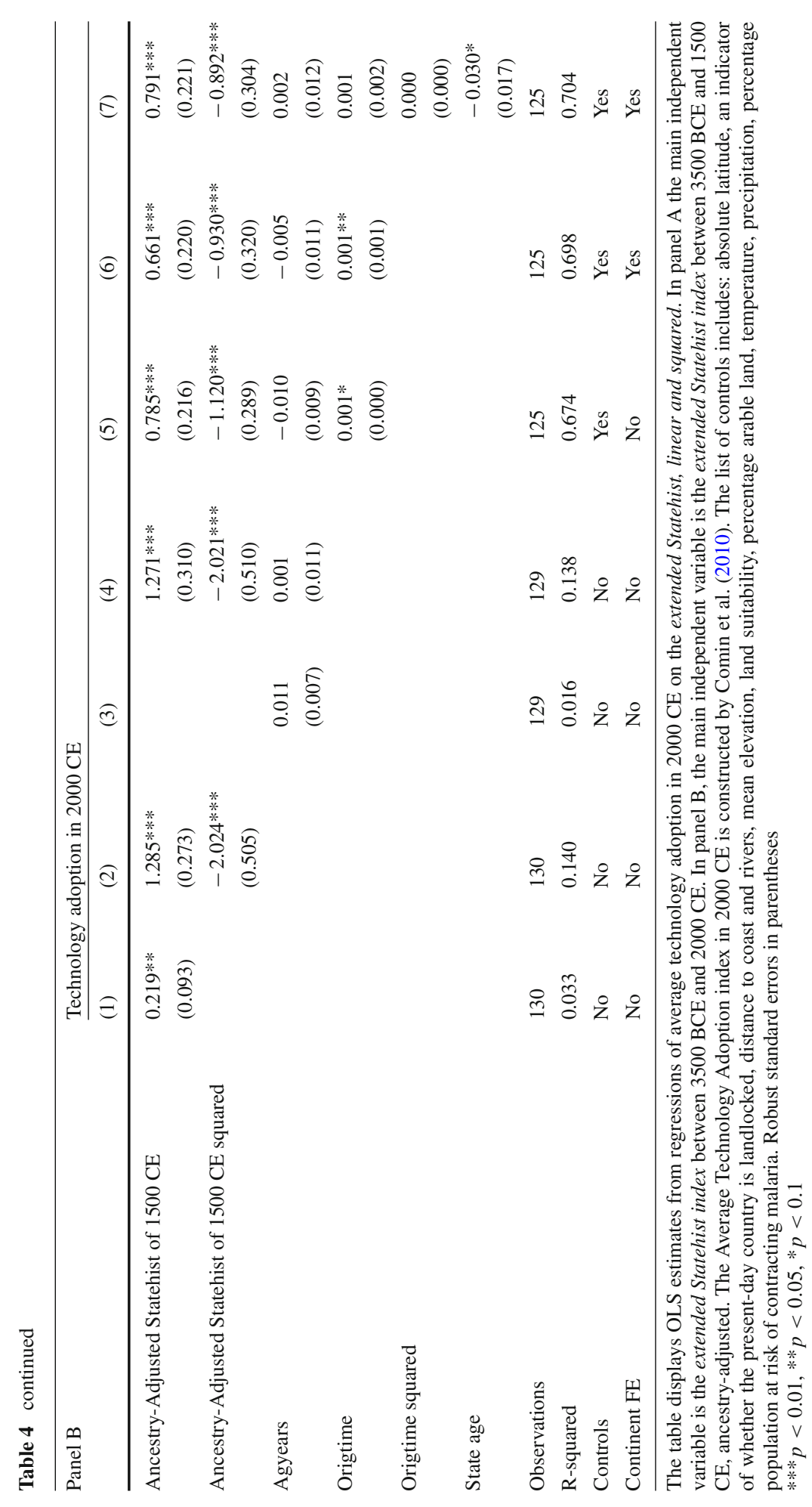




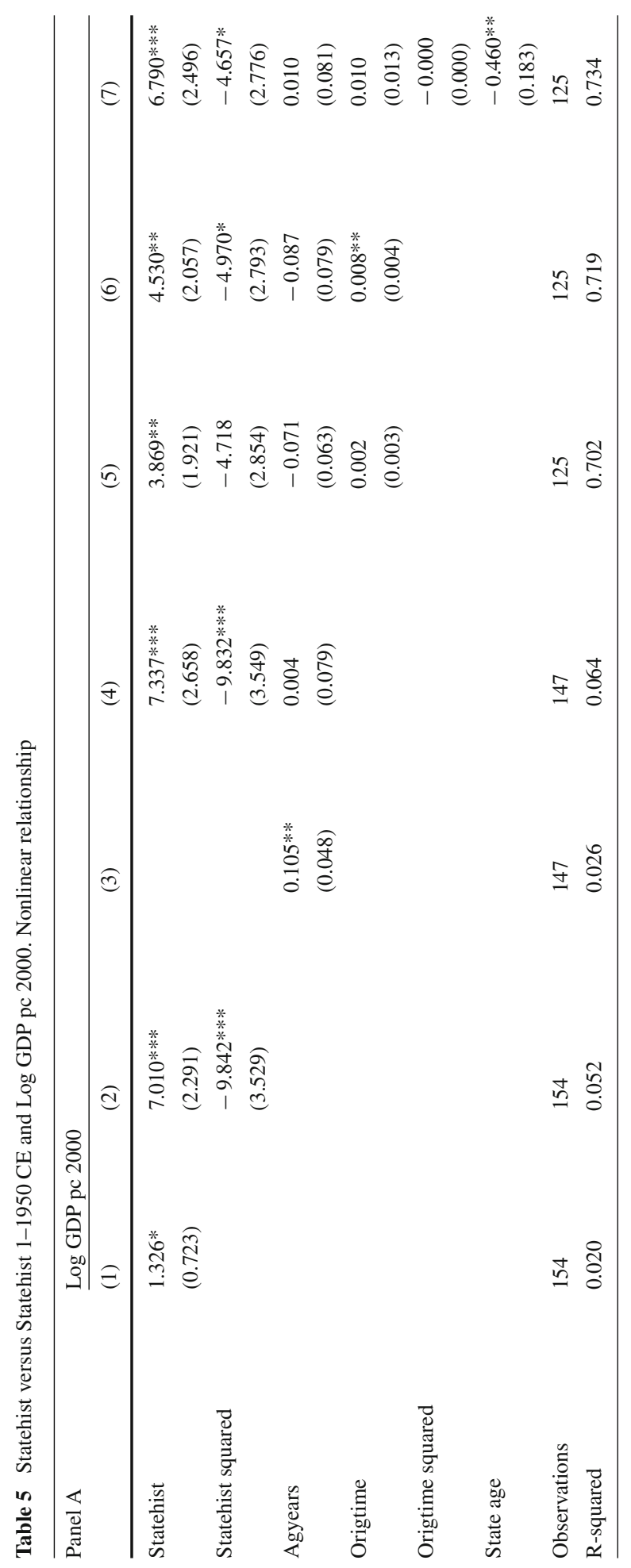




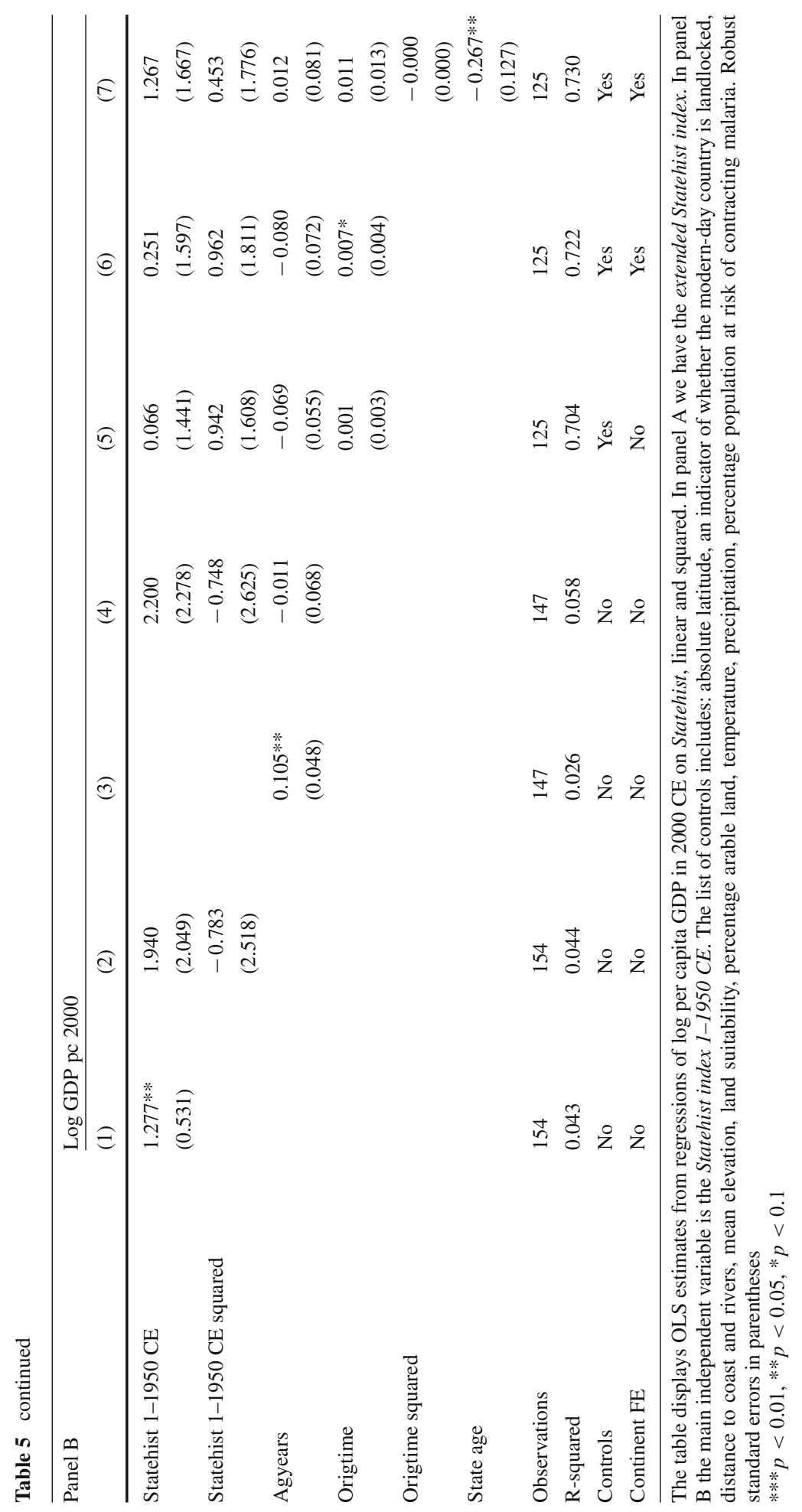




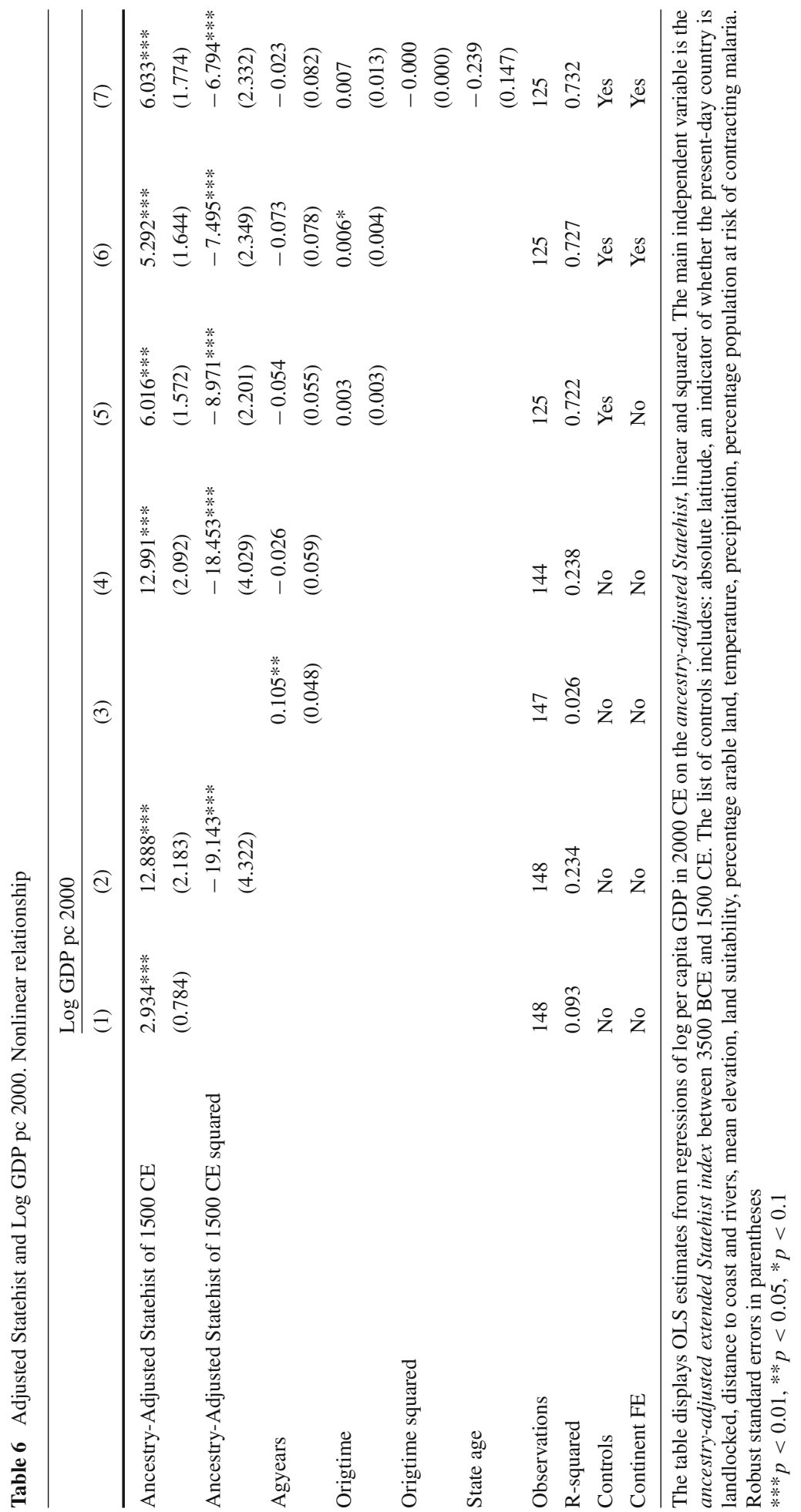




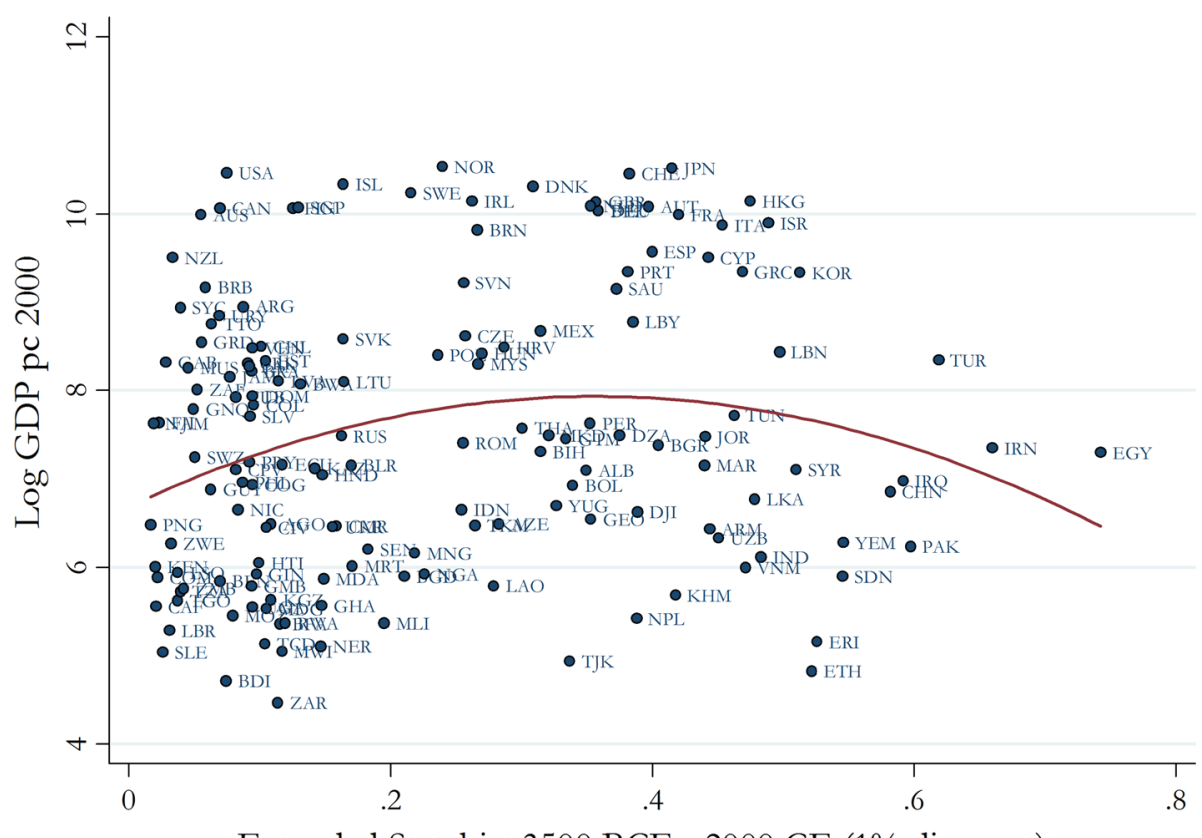

Extended Statehist 3500 BCE - 2000 CE (1\% discount)

Fig. 4 Non-linear relationship between Log GDP per capita in 2000 and Statehist index. Note: The figure shows a fitted quadratic regression line corresponding to the estimates in Table 5, panel A, column 2, with 154 country observations distinguished by 3-letter country isocodes. On the Y-axis we have the logarithm of GDP per capita in 2000 and on the X-axis we have the extended Statehist (see Eq. (3) above). An increase in Statehist by 0.1 is interpreted approximately as an additional 300 years of effective fully autonomous statehood

1-1950 CE displays coefficients with the same signs but much smaller and insignificant (the coefficient of the quadratic term becomes positive when controls are included). ${ }^{42}$

While Agyears is significantly positively correlated with modern-day GDP (column 3), when we control for it alongside the linear and quadratic Statehist, its inclusion hardly changes the signs and the magnitudes of the coefficients of the Statehist terms. Moreover, the effect of the time from transition to agriculture is insignificant when the Statehist terms are added (column 4), indicating that although early states may only have arisen where agriculture had long been practiced, a country's subsequent experience with states eclipses its experience of agriculture as a predictor of current productivity. As with technology, the concavity is robust to using alternative discount rates (0.1 and $2 \%)$ to calculate Statehist (Appendix Tables D5D6). Moreover, separate linear estimates below and above the maximizing Statehist display a large, significant downward slope for countries in the upper range, consistent with Fig. 4 (Table D6, in the online Appendix). ${ }^{43,44}$ This confirms that a very limited or very extensive experience with state institutions can become a relative disadvantage across nations.

\footnotetext{
42 Note that we obtain similar estimates if we use the 1-2000 CE Statehist index instead, meaning that the 1951-2000 CE period is not what is driving the quadratic relationship documented in panel A.

43 With a lower discount factor of $0.1 \%$, we still find a negative, (albeit insignificant for log GDP per capita) linear relationship on the portion above the maximizing level of Statehist implied from the quadratic specifications not including any controls. We find a significant negative linear relationship for the high Statehist countries with discount factor $2 \%$, so a qualitatively similar outcome appears over the broad range of discount factors, at least spanning $0.1-2 \%$. Hence the results are not ultra-sensitive over a range of potential weights the BCE part could receive.

44 Results of this test are very similar if we control for the time since the Neolithic transition.
} 
The concavity results are robust to the inclusion of Origtime, as well as geographical controls and continent fixed effects. ${ }^{45}$ However, the coefficients on Statehist squared are smaller than the linear terms' coefficients as more controls are introduced in columns (5)(7). This implies that the optimum level of Statehist falls very close to, or outside the top of its range. Does this mean that the hump-shaped relationship between state history and income suggested by the earlier estimates (e.g., columns 2 and 4) is mistaken? We think not. Our framework posits such a relationship between state history and productivity as emerging across countries, whereas each individual country's trajectory is described by a logistic curve, with no downward sloping portion (see the left side of Fig. 1a). As the number of factors controlled by our regressions grows, we may be approaching a situation in which the estimated coefficients on the focal Statehist variables will reflect only differences between otherwise nearly identical countries within a very narrow sub-region (countries not only in the same continent but sharing almost identical geographic coordinates, climate, etc.), as well as a very similar date of state origins, as indicated by the inclusion in column (7) of the variable state age. The resulting estimates of concavity without evidence of a downward sloped portion is consistent with the logistic curve pattern expected for any single country (left side of Fig. 1a) rather than the hump shape predicted for the full cross-section of countries over which state histories show wider variation.

Is our finding of concavity of per capita GDP with respect to state history in fact attributable to having included coding of state presence in the BCE era in our analysis, unlike previous studies? To see that this is the case, compare panel B of Table 5, which shows estimates of similar specifications but using the old state history variable covering years 1-1950 CE only. The main estimates are neither significant nor similar in terms of signs with the estimates in panel A.

Lastly, from column (2) in Table 5, based on the estimates of our coefficients of interest, we can infer that the predicted income-maximizing level of Statehist is reached at 0.355 , which is very close to that of the United Kingdom and most countries in Western Europe.

The effects' magnitudes are not straightforward to assess from the tables. However, some numerical examples may show more clearly how the impact upon per capita GDP of an increase in Statehist depends on the level of state experience at which the change occurs. Take for instance the case of Indonesia, which has 1350 years of state existence and a Statehist score of 0.254 . If we could hypothetically increase the Statehist score by 0.1 (which is $58 \%$ of Statehist's standard deviation, but enough to add 335 full-state years making it reach the level of the UK score), the implied approximate effect on per capita GDP in 2000 would be roughly a $20 \%$ increase, from USD 773 to USD 944 in $2000 .{ }^{46}$ The opposite would happen if we were to increase the value of the Statehist score by 0.1 for China, which starts off with a value of 0.582 (a value exceeded by only five countries in the sample): the approximate effect would be a drop in per capita GDP in 2000 by $44.4 \%$.

Taken together, our estimation results so far are consistent with our predicted pattern. Moreover, this becomes evident only when we employ the new extended Statehist index. Are the estimates improved by accounting for the state histories of the ancestors of presentday populations, instead of the state histories of places? To investigate this, we estimate the model for per capita GDP above using the ancestry-adjusted Statehist index. The results are

\footnotetext{
45 We also explore alternative specifications in Tables D9 and D10 in the Appendix, where we include linear and squared variables such as the time since transition to agriculture, state age, absolute latitude, migratory distance from Addis Ababa, and predicted genetic diversity (where the latter two are taken from Ashraf and Galor 2013). Our main coefficients of interest are robust.

46 The exact calculation based on estimates in column 2 of panel A is $[(7.010-2 \cdot 9.842 \cdot 0.254) / 10] \cdot 100 \%=$ $20.1 \%$.
} 
displayed in Table 6, where we use the Statehist index in $1500 \mathrm{CE}$ adjusted by the migration matrix (as in previous studies, but for the first time including full state history before $1 \mathrm{CE}$ ) ${ }^{47}$

We find that the concave relationship between per capita income and the ancestry-adjusted Statehist is robust to all specifications and that the coefficients of interest are significant at $1 \%$ level in all columns in panel A. Moving from a linear (column 1) to a quadratic function (column 2) in Statehist as in all other tables, greatly improves the goodness of fit, strengthening the case for a nonlinear specification. Moreover, the explanatory power of the model (as measured by the regression R-squared) when we introduce only the ancestryadjusted Statehist terms (column 2) is now $23.4 \%$ versus $5.2 \%$ for unadjusted Statehist. ${ }^{48}$

In the online Appendix Table D12 we look at how sensitive the results from specifications where we include controls and county fixed effects are to excluding various countries from the sample. The estimates describing a concave function are significant when we exclude in turn the Middle-East and Sub-Saharan Africa, but the standard errors increase and the Statehist squared is insignificant when we exclude both these and North Africa (column 4). This is because this exclusion takes away a large part of the variation in Statehist that is due to very short and very long state age. Nevertheless, the signs and magnitudes of the coefficients point to the same concave relationship. There is no evidence of a concave relationship in the sample of European colonies, which are all very young and with little experience with home-based rule relative to the rest of the sample (median age 550 years and average 1180 years). ${ }^{49}$

\subsection{Statehist mechanisms}

So far we have looked at the accumulated Statehist, which summarizes via their interaction (i) the variation in state age (the time elapsed since the first occurrence of $z^{1}>0$ ), ${ }^{50}$ (ii) the degree to which the state was home-based $\left(z^{2}\right)$, and (iii) the state's territorial completeness and unity $\left(z^{3}\right)$. In this sub-section, we briefly investigate the distinct effects of those three components and their respective contributions to the inverse-u shape. In Appendix Table D13, we estimate variants of columns (1), (2), (5) and (7) from Table 2, replacing Statehist with each of its components, in turn. Without controls (column 2), a quadratic relationship is found for each component (panels A-C), although for $z^{3}$ (territorial completeness), the coefficients in quadratic specification (2) are not statistically significant, whereas when included alone, the level term attains a positive coefficient (in column 1) that is significant at the $5 \%$ level.

\footnotetext{
47 Note that we use state history only up to 1500 , rather than to 2000 . This is because there are no systematic data on the timing of the migrations during the half millennium 1500-2000. We have estimated the same model using an alternative measure of state experience combining the ancestry-adjusted Statehist of $1500 \mathrm{CE}$ with the unadjusted Statehist score for the period 1500-2000. The results are similar to the estimates in Table 5.

48 The explanatory power in column 7 across all the tables is around $1 \%$ point larger than when we only include the linear Statehist (results available upon request). As with the unadjusted Statehist, we also explore alternative specifications in the online Appendix Table D10, including various controls in linear and squared form and the results are consistent across all columns.

49 We also run some sensitivity checks to see if the estimated concavity conditional on controls is merely reflecting some unobserved heterogeneity between countries or regions, such as the Middle-East, North Africa and Sub-Saharan Africa. In the online Appendix Table D11 we present the baseline specifications from Tables 5 and 6, panel A, column (7) followed by similar specifications amended to include controls for the aforementioned regions (column 2), a dummy for former European colonies (column 3) and legal origin controls (column 4). The estimates are very similar to those in the baseline specifications.

50 For convenience of interpretation, the exercise in this section uses state age (years since first state appearance) rather than discounted $z^{1}$. While the latter can revert to 0 or 0.75 after periods with value 1 due to state collapse or existence of a macro-political vacuum following contraction of an outside empire, such cases are extremely rare in practice, hence the difference between discounted $z^{1}$ and state age is almost entirely attributable to not applying discounting to the latter.
} 
When all three separate component terms are included simultaneously, in panel D, the results are similar. Two of the three components (state age, and territorial completeness/unity) also obtain highly significant positive coefficients in a strictly linear specification (column 1). Taken together, these results support that each component, not only state age, has some importance in its own right, a finding not explored in previous studies. When additional controls are added in column (3), and continent fixed effects as well in column (4), only the coefficient on level of $z^{2}$ (home rule) remains statistically significant. Its positive sign suggests that having been independent rather than part of an externally based empire is most robustly and significantly associated with favorable outcomes, among the three components. ${ }^{51}$

\subsection{Borders endogeneity and spatial dependence}

We now turn to the issue of whether endogeneity of borders raises concerns about the reliability of our findings. Throughout history, borders shifted as states consolidated or weakened their administrative or military capacities, or incurred political regime changes. For instance, Alesina and Spolaore (1997) showed that democratization can lead to secession, an example of which is the case of the Balkan countries. Gennaioli and Voth (2015) showed that the post-1500 military innovations in Europe led to more efficient warfare, stronger state capacity to finance warfare, and imminent territorial conquests or redistribution, which have redefined country borders. Their examples of Silesia, Alsace-Lorraine, and the Duchy of Milan are joined by numerous others, such as the regions split in the Peace of Westphalia in 1648 amongst Sweden, France, The Dutch Republic, Spain and the Holy Roman Empire. European colonisation is a leading example where late comers, having overtaken older states, proceeded to redraw the borders of these states in Latin America, North Africa, the Middle East and the Indian subcontinent. Against this backdrop, defining the state experience and economic indicators on the basis of present-day country borders may induce several risks.

First, there is a risk of retroactive measurement error, due to the fact that the current countries' territories used to compute historical values of Statehist often bear little resemblance with the geopolitical logic in ancient times (with a few exceptions like Norway, Sweden, and Japan). We should note that our definition of Statehist requires keeping track of the changing boundaries of states-of-the-time within and across half-centuries, and the scores account for multiple polities, the internal or external basis of their rule and the percentage of territory they occupied within what may be thought of as an arbitrarily defined territory, from the standpoint of early periods. Although the state presence in some polities or sub-territories may be measured with error, if this error is random, at worst our estimates are biased towards zero. It would be more difficult to predict the bias if measurement error was correlated with the outcome variables, e.g. if borders shifted through conquest or colonization to include territories with more/less state history, productivity and technological sophistication, potentially also associated with the accuracy of data sources. Even so, the amalgamation of low information areas together into countries with better information and more state history is likely to lead to

51 Note that even though a discount rate of $1 \%$ only is applied, more weight is nonetheless placed on the past two and especially the last millennium than on earlier times. Hence, the long periods following earliest antiquity during which such ancient cradles of civilization as today's Egypt and Iraq were colonies of the Roman, Byzantine, Mongol, Ottoman, and other empires, can cause their relatively low incomes today to be attributed in part to this term. The ancient experiences of parts of today's UK, Germany, or Belgium as one-time Roman colonies, on the other hand, receives less weight given the many centuries of home-based rule that were present thereafter. Countries with no state in our sense prior to the European colonial epoch, coded as colonies during that time-for example Dominican Republic, Brazil, Zambia, Mozambique-have $z^{2}$ of 0 or 0.5 in those eras, their middle or low incomes today also accordingly helping to explain the strength of the coefficient on $z^{2}$. 
a reduction of error for the low Statehist parts of those countries, since the histories of such areas are typically better documented than are those of otherwise similar areas more distant from record-keeping societies. A second concern is that, as discussed earlier, productivity and technological sophistication sometimes drive conquest, moving borders and influencing state history. While we cannot fully dismiss the problem of endogenous borders, the issue of selection into state history is partly mitigated in cross-country regressions with contemporaneous economic development by the fact that whatever state-level polities existed at this and that period within the boundaries of what are today countries have changed their borders on many occasions and for a wide variety of reasons.

An alternative to using country borders could have been to divide the world randomly into equal-sized grid cells and then study the history of states and economic development in each such cell (e.g. Michalopoulos 2012). State history has been coded at the grid-cell level for sub-Saharan Africa after 1000 CE by Depetris-Chauvin (2014). For the present study, however, this would require constructing disaggregated data on a global scale for nearly six thousand years. The challenge with this approach, in addition to the sheer magnitude of the exercise, would be the precarious state history information for many grid cells. Average quality of data may well be higher with the countries-of-today approach than would be achievable with grid cells, unless a research effort several orders-of-magnitude larger were undertaken. With these caveats in mind, to the extent that researchers are interested in tracking the histories of countries in order to understand contemporary levels of development, the modern configuration of countries is still a natural point of departure.

A third concern, which is particularly salient in the context of jointly determined borders, is that the histories and outcomes of neighbouring countries transcend national boundaries. Countries in the same geographical or geopolitical regions tend to have correlated productivity levels and experience similar productivity shocks, for instance through contemporary diffusion of new technologies. In the presence of such spatial spillovers, the standard assumptions on the independence of observations are violated, and OLS regressions might yield biased and inefficient estimates. In this case, modelling spatial dependence is a more suitable approach. To account for potential spatial autocorrelation in the disturbances, we estimated alternative regressions using the Conley (1999) correction of the standard errors. ${ }^{52}$ The results, displayed in Appendix Table D17 (panel A for Statehist and panel B for Ancestry-Adjusted Statehist) are very similar to the counterparts in Tables 5 (panel A) and 6, despite the fact that standard errors are, if anything, slightly larger than in the OLS regressions. We also estimate models where we allow the dependent variable to be a function of neighbouring countries' outcomes (the spatial autoregressive model-SAR) and where we allow both the dependent variable and the errors terms to follow spatial autoregressive processes (SARAR) ${ }^{53}$ In both models we input a matrix of weights given by the inverse great-circle distances between geodesic centroids. ${ }^{54}$ Appendix Tables D18 and D19 show that the results with the Ancestry-Adjusted Statehist are robust across models, and that the SARAR results for Statehist generate qualita-

\footnotetext{
52 The idea is that covariance matrices are weighted by the inverse of the distance between countries, with the weights becoming null after a specified threshold. In this case, we have set a threshold of twenty coordinate degrees, but the results are robust to various thresholds.

53 Spatial autocorrelation models are increasingly used in long-run growth studies. See e.g. Ashraf and Michalopoulos (2015) and Ashraf and Galor (2013). The typical approach, which we also adopt, is the maximum likelihood estimator from Drukker et al. (2013), implemented in Stata through the spreg command.

54 SARAR models are $\mathbf{y}=\lambda \mathbf{W y}+\mathbf{X} \boldsymbol{\beta}+\mathbf{u}$, with $\mathbf{u}=\rho \mathbf{M u}+\boldsymbol{\epsilon}$, where $\mathbf{W}$ and $\mathbf{M}$ are $n \times n$ spatial weighting matrices, $n$ is the sample size, $\lambda$ and $\rho$ are scalars, and $\mathbf{W y}$ and $\mathbf{M u}$ are $n \times 1$ vectors representing spatial lags. We estimate a model where $\mathbf{W}=\mathbf{M}$ is a matrix with diagonal elements equal to zero, and off-diagonal elements representing the inverse great-circle distances between geodesic centroids. In a SAR model, the difference is that $\mathbf{u}$ is assumed to be independently and identically distributed.
} 
tively similar but insignificant results. We also report the SARAR estimates using a contiguity matrix defined not by geographical proximity, but by whether countries share the same legal origins (Appendix Table D20). ${ }^{55}$ All results hold, with the linear and squared terms of both extended and Ancestry-Adjusted indices remaining significant. In sum, accounting for spatial spillovers does little to affect the results with extended state history and leaves the results with Ancestry-Adjusted indices unchanged. ${ }^{56}$

\section{Discussion and conclusions}

To sum up, we have presented a model of the role of state history in economic development wherein growing state experience is associated with increases in productivity in the individual country, but where countries with less history of state presence may have a productivity advantage compared to ones with more experience of state institutions. We have coded and assembled a comprehensive data series on state history from state emergence (which often occurred before the Common Era) to $2000 \mathrm{CE}$ for a sample of 159 countries, building on the previously constructed State antiquity index of Bockstette et al. (2002). The resulting empirical analysis revealed consistent reduced-form regressions, where a hump-shaped relationship is confirmed between extended Statehist and technology and economic development in $2000 \mathrm{CE}$. This relationship is robust to using a fairly wide range of discounts of the past, to controlling for duration of reliance on agriculture, and to assuming that migrants beginning with the age of European colonization carried the state experience of their home countries with them in the form of a portable and transmissible cultural heritage. Although the estimated coefficients cease to indicate an absolute decline in income at the highest levels of state experience after the addition of enough controls, this finding is consistent with the relationship being concave and monotonic within the individual country, the hump-shaped pattern being predicted only for cross-country and evidently cross-regional comparison at a particular historical juncture.

Although an extensive analysis of the causal mechanisms is beyond the scope of this paper, we believe we have offered support from the literature that improvements in the quality of institutions that are more easily achieved by states of intermediate age provide a plausible explanation for this pattern. Our finding appears to be consistent with the fact that while there is indeed a great deal of persistence of early societal advantages, it is also the case that the technological and institutional know-how of societies can slowly diffuse to neighbouring societies through migration or trade. These societies with younger states and/or a higher degree of autonomy can then pick the best practices of the older societies and potentially avoid some of the pitfalls that might have become a drag for the old civilizations.

State capacity might be one example of such institutional transfer across state borders. The ability to levy taxes and to consolidate an administrative infrastructure has recently been shown to produce regional spill-overs to neighbouring areas' economic performance

\footnotetext{
55 The diagonal elements of this spatial weighting matrix are zero, and the off-diagonal elements are 1 if countries $i$ and $j$ have the same legal origins, regardless of whether they are British, French, Socialist, German or Scandinavian

56 The latter supports not only the robustness of our general finding about the inverse-u shape, but also Putterman and Weil's point that effects of early state experience on current day economic outcomes are better manifested when we take into account that the contemporary populations of many countries, e.g. in the Americas and Oceania, are mostly descendants of people from other countries who carry those countries' cultural and institutional experiences with them. This is also consistent with Lagerlöf (2016) results showing concavity with the CE part of Statehist when accounting for migration.
} 
(Acemoglu et al. 2015). Such spill-overs might occur more easily, however, among countries sharing similar histories, including depth of experience with centralized authority.

There are also other factors that have been proposed for explaining the reversal in the Western core, including environmental degradation in the Fertile Crescent and in parts of the Mediterranean region. Once agriculture spread out of the Fertile Crescent, the more robust loess soils of northern Europe, combined with a reliance on rain rather than irrigation for cultivation, proved to be an advantage in the long run (Jones 1981). It has also been suggested that the rise and fall of dominant empires of the Western core followed cycles of expansion, over-extension, and eventually decline, with a gradual shift of power towards the northwest (Kennedy 1989). Acemoglu et al. (2005) show that the emergence of Atlantic trade after $1500 \mathrm{CE}$ had a major impact on the rise of for instance Spain and the United Kingdom. ${ }^{57}$

A similar process can potentially explain comparative development in East Asia. Japan's less powerful central court and greater perceived vulnerability to potential Western colonizers led it to undertake decisive modernization measures almost a century before China. This development had spillover effects on Korea and Taiwan, all young states in comparison with China.

In summary, the new pattern uncovered by the extended Statehist shows that although greater depth of state experience is associated with better economic outcomes when the measure used emphasizes mainly the millennium before 1500, the relationship of state history to income and technology includes a range of excessive age or senescence, if we account for the BCE millennia and give them sufficient weight. We leave it for future work to attempt to identify the exact mechanisms behind this pattern. However, we believe caution is recommended against the interpretation of these disadvantages as fully automatic and insurmountable consequences of long state histories. Our view is not that a long uninterrupted state history is always bad for economic development and as such undesirable. We believe this is a story of moderation in the exercise of centralized power and adaptability of the state institutions to the ever-changing economic realities. While those in the middle range of state history have thus far exhibited such moderation and adaptability more effectively, on average, there remains a considerable space of indeterminacy within which political actors may still exert influence over their countries' fates.

Open Access This article is distributed under the terms of the Creative Commons Attribution 4.0 International License (http://creativecommons.org/licenses/by/4.0/), which permits unrestricted use, distribution, and reproduction in any medium, provided you give appropriate credit to the original author(s) and the source, provide a link to the Creative Commons license, and indicate if changes were made.

\section{References}

Acemoglu, D., Garcia-Jimeno, C., \& Robinson, J. (2015). State capacity and economic development: A network approach. American Economic Review, 105(8), 2364-2409.

Acemoglu, D., Johnson, S., \& Robinson, J. (2001). The colonial origins of comparative development: An empirical investigation. American Economic Review, 91(5), 1369-1401.

57 Acemoglu et al. (2001) argue that there was also a reversal among former colonies such that relatively less advanced pre-colonial societies had an inflow of European migrants who installed strong institutions that still persist today, although Glaeser et al. (2004) and Chanda et al. (2014) question whether European institutions rather than European human capital is the decisive factor. Hariri (2012) argues that non-European countries with older states that resisted European colonization had worse economic outcomes in the modern era due to the persistently autocratic nature of their states. 
Acemoglu, D., Johnson, S., \& Robinson, J. (2002). Reversal of fortunes: Geography and institutions in the making of the modern world income distribution. Quarterly Journal of Economics, 117(4), 1231-1294.

Acemoglu, D., Johnson, S., \& Robinson, J. (2005). Institutions as the fundamental cause of long run economic growth. In P. Aghion \& S. Durlauf (Eds.), Handbook of economic growth. Amsterdam: North-Holland.

Acemoglu, D., \& Robinson, J. (2012). Why nations fail: The origins of power, prosperity and poverty. New York: Crown Business.

Ahlerup, P., \& Olsson, O. (2012). The roots of ethnic diversity. Journal of Economic Growth, 17(2), 71-102.

Alesina, A., \& Spolaore, E. (1997). On the number and size of nations. The Quarterly Journal of Economics, 112(4), 1027-1056.

Ang, J. (2013a). Are modern financial systems shaped by state antiquity? Journal of Banking and Finance, $37(11), 4038-4058$.

Ang, J. (2013b). Institutions and the long-run impact of early development. Journal of Development Economics, $105,1-18$.

Ashraf, Q., \& Galor, O. (2011). Dynamics and stagnation in the Malthusian epoch. American Economic Review, 101(5), 2003-2041.

Ashraf, Q., \& Galor, O. (2013). The 'out of africa' hypothesis, human genetic diversity, and comparative economic development. American Economic Review, 103(1), 1-46.

Ashraf, Q., \& Michalopoulos, S. (2015). Climatic fluctuations and the diffusion of agriculture. The Review of Economics and Statistics, 97(3), 589-609.

Besley, T., \& Persson, T. (2009). The origins of state capacity: Property rights, taxation and politics. American Economic Review, 99(4), 1218-1244.

Besley, T., \& Persson, T. (2013). Taxation and development. In A. Auerbach, R. Chetty, M. Feldstein, \& E. Saez (Eds.), Handbook of public economics (Vol. 5, No. 2, pp. 51 - 110).

Bockstette, V., Chanda, A., \& Putterman, L. (2002). States and markets: The advantage of an early start. Journal of Economic Growth, 7(4), 347-69.

Carneiro, R. L. (1970). A theory of the origin of the state. Science, 169, 733-38.

Carneiro, R. L. (1981). The chiefdom: Precursor of the state. In G. D. Jones \& R. R. Kautz (Eds.), The transition to statehood in the new world (pp. 37-79). Cambridge: Cambridge University Press.

Chanda, A., Cook, A., \& Putterman, L. (2014). Persistence of fortune: Accounting for population movements, there was no post-columbian reversal. American Economic Journal: Macroeconomics, 6(3), 1-28.

Chanda, A., \& Putterman, L. (2005). State effectiveness, economic growth, and the age of states. In M. Lange \& D. Rueschemeyer (Eds.), States and development: Historical antecedents of stagnation and advance (pp. 69-91). Basingstoke: Palgrave MacMillan.

Chanda, A., \& Putterman, L. (2007). Early starts, reversals and catch-up in the process of economic development. Scandinavian Journal of Economics, 109(2), 387-413.

Cinyabuguma, M., \& Putterman, L. (2011). Sub-Saharan growth surprises: Being heterogeneous, inland and close to the equator does not slow growth within Africa. Journal of African Economies, 20(2), 217-262.

Collier, P. (2009). The political economy of state failure. Oxford Review of Economic Policy, 25(2 2009), 219-240.

Comin, D., Easterly, W., \& Gong, E. (2010). Was the wealth of nations determined in 1000 BC? American Economic Journal: Macroeconomics, 2(3), 65-97.

Conley, T. G. (1999). GMM estimation with cross sectional dependence. Journal of Econometrics, 92(1), $1-45$.

Cox, G. W., \& Weingast, B. R. (2015). Executive constraint, political stability and economic growth. Available at SSRN http://ssrn.com/abstract=2618059 or https://doi.org/10.2139/ssrn.2618059.

Daniele, V. (2013). Does the intelligence of populations determine the wealth of nations? Journal of SocioEconomics, 46, 27-37.

Depetris-Chauvin, E. (2014). State history and contemporary conflict: Evidence from Sub-Saharan Africa. Unpublished working paper, Brown University.

Diamond, J. (1997). Guns, Germs, and Steel: The Fates of Human Societies. New York, NY: Norton.

Diamond, J., \& Bellwood, P. (2003). Farmers and their languages: The first expansions. Science, 300(5619), 597-603.

Dincecco, M., \& Katz, G. (2014). State capacity and long-run economic performance. The Economic Journal,. https://doi.org/10.1111/ecoj.12161.

Drukker, D. M., Prucha, I. R., \& Raciborski, R. (2013). Maximum likelihood and generalized spatial two-stage least-squares estimators for a spatial-autoregressive model with spatial-autoregressive disturbances. Stata Journal, 13(2), 221-241.

Earle, T. K. (1987). Chiefdoms in archaeological and ethnohistorical perspective. Annual Review of Anthropology, 16, 279-308. 
Ertan, A., Fiszbein, M., \& Putterman, L. (2016). Who was colonized and when? A cross-country analysis of determinants. European Economic Review, 83, 165-184.

Flannery, K. V. (1995). Prehistoric social evolution. In M. Ember (Ed.), Research frontiers in anthropology (pp. 1-26). Englewood Cliffs, NJ: Prentice-Hall.

Galor, O., \& Moav, O. (2007). The neolithic revolution and contemporary variations in life expectancy. Working Papers 2007-2014, Department of Economics, Brown University.

Gennaioli, N., \& Voth, H. J. (2015). State capacity and military conflict. Review of Economic Studies, 82, 1409-1448.

Glaeser, E. L., La Porta, R., Lopez-de-Silanes, F., \& Shleifer, A. (2004). Do institutions cause growth? Journal of Economic Growth, 9(3), 271-303.

Hall, R. E., \& Jones, C. I. (1999). Why do some countries produce so much more output per worker than others? Quarterly Journal of Economics, 114(1), 83-116.

Hariri, J. G. (2012). The autocratic legacy of early statehood. American Political Science Review, 106(3), 471-494.

Hibbs, D. A., \& Olsson, O. (2004). Geography, biogeography, and why some countries are rich and others are poor. Proceedings of the National Academy of Sciences, 101, 3715-3720.

Iliev, P., \& Putterman, L. (2007). Social capability, history and the economies of communist and postcommunist states. Studies in Comparative International Development, 42(1), 36-66.

Johnson, A., \& Earle, T. (2000). The evolution of human societies: From foraging group to agrarian state (2nd ed.). Stanford: Stanford University Press.

Jones, E. L. (1981). The European miracle: Environments, economies and geopolitics in the history of Europe and Asia. Cambridge: Cambridge University Press.

Jones, G. D., \& Kautz, R. R. (1981). Issues in the study of new world state formation. In G. Jones \& R. Kautz (Eds.), The transition to statehood in the new world (pp. 3-34). Cambridge: Cambridge University Press.

Kennedy, P. (1989). The rise and fall of the great powers. New York: Vintage Books.

Lagerlöf, N. (2016). Statehood, democracy and preindustrial development. Journal of Economic Dynamics and Control, 67, 58-72.

Marcus, J. (1992). Dynamic cycles of Mesoamerican states: Political fluctuations in Mesoamerica. National Geographic Research and Explorations, 8, 392-411.

Mayshar, J., Moav, O., Neeman, Z., \& Pascali, L. (2015). Cereals, appropriability and hierarchy. CEPR Discussion Paper 10742.

McEvedy, C., \& Jones, R. (1978). Atlas of world population history. New York, NY: Penguin Books Ltd.

Michalopoulos, S. (2012). The origins of ethnolinguistic diversity. American Economic Review, 102(4), 15081539.

Morris, I. (2010). Why the west rules-for now: The patterns of history, and what they reveal about the future. London: Profile Books.

North, D. (1990). Institutions, institutional change and economic performance. Cambridge: Cambridge University Press.

Olson, M. (1993). Dictatorship, democracy, and development. American Political Science Review, 87(3), $567-576$.

Olsson, O., \& Hibbs, D. (2005). Biogeography and long-run economic development. European Economic Review, 49(4), 909-938.

Olsson, O., \& Paik, C. (2013). A western reversal since the neolithic: The long-run impact of early agriculture. Mimeo, University of Gothenburg.

Olsson, O., \& Paik, C. (2016). Long-run cultural divergence: Evidence from the neolithic revolution. Journal of Development Economics, 122, 197-213.

Peregrine, P. N. (2003). Atlas of cultural evolution. World Cultures: Journal of Comparative and Cross-Cultural Research, 14(1), 1-75.

Puga, D., \& Trefler, D. (2014). International trade and institutions change: Medieval Venice's response to globalization. Quarterly Journal of Economics, 129, 753-821.

Putterman, L., \& Trainor, C. A. (2006). Agricultural transition year: Country data set. http://www.econ.brown. edu/fac/louis_putterman/.

Putterman, L., \& Weil, D. N. (2010). Post-1500 population flows and the long-run determinants of economic growth and inequality. The Quarterly Journal of Economics, 125(4), 1627-1682.

Rostow, W. (1960). The five stages of growth: A non-communist manifesto. Cambridge: Cambridge University Press.

Service, E. R. (1962). Primitive social organization: An evolutionary perspective. New York: Random House. Simonsohn, U. (2016). Two lines: The first valid test of $U$-shaped relationships. Mimeo, University of Pennsylvania. 
Spencer, C. S. (1990). On the tempo and mode of state formation: Neoevolutionism reconsidered. Journal of Anthropological Archaeology, 9, 1-30.

Spencer, C. S., \& Redmond, E. M. (2004). Primary state formation in Mesoamerica. Annual Review of Anthropology, 33, 173-99.

Tilly, C. (1990). Coercion, capital and European states. AD 990-1990, Oxford.

Voigtlander, N., \& Voth, H. J. (2013). The three horsemen of riches: Plague, war and urbanization in early modern Europe. Review of Economic Studies, 80(2), 774-811.

Weber, M. (1968). In G. Ross \& C. Wittich (Eds.), Economy and society. New York: Bedminster Press Incorporated.

Wittfogel, K. A. (1957). Oriental despotism: A comparative study of total power. New Haven: Yale University Press.

Yoffee, N. (1988). The collapse of ancient Mesopotamian states and civilization. In N. Yoffee \& G. L. Cowgill (Eds.), The collapse of ancient states and civilizations. Tucson: University of Arizona Press. 